ISSN 1936-5098

CAE Working Paper \#11-04

\title{
Strategic Analysis of Influence Peddling
}

by

$$
\begin{gathered}
\text { Mukul Majumdar } \\
\text { and } \\
\text { Seung Han Yoo }
\end{gathered}
$$

July 2011 


\title{
Strategic Analysis of Influence Peddling*
}

\author{
Mukul Majumdar ${ }^{\dagger}$ and Seung Han $\mathrm{Yoo}^{\ddagger}$
}

February 20, 2011

\begin{abstract}
This paper analyzes "Influence Peddling" with interaction between human capital transfer and collusion-building aspects in a model, in which each government official regulates multiple firms simultaneously. We show that (i) there exists an "optimal" division rule for collusion between a sequence of "qualified" regulators and a firm; (ii) as the regulators increasingly benefit from the collusion, they strictly decrease regulation rates for the firm under collusion while strictly increasing regulation rates for a firm not under collusion; and (iii) post-government-employment restrictions are not "effective" policies, and an alternative policy can be suggested.
\end{abstract}

Keywords and Phrases: revolving doors, signaling games, repeated games JEL Classification Numbers: D73, H83, L51

\footnotetext{
${ }^{*}$ We are grateful to Geir Asheim, Parimal K. Bag, Talia Bar, Kaushik Basu, Yeon-Koo Che, Ani Guerdjikova, Byoung Heon Jun, John Quah, Roland Strausz and Shmuel Zamir for helpful comments and suggestions. Thanks are due to seminar participants at The Royal Economic Society Third PhD Presentation Meeting at UCL, The International Meeting for Public Economic Theory (PET 08), Cornell, Hanyang, Korea, NUS, Waseda, Yonsei University, KAIST, KIPF, KISDI and KDI for comments. Of course, all remaining errors are ours.

${ }^{\dagger}$ Department of Economics, Cornell University, 460 Uris Hall, Ithaca, NY 14853, USA (e-mail: mkm5@cornell.edu).

${ }^{\ddagger}$ Division of Economics, Nanyang Technological University, 14 Nanyang Drive, Singapore 637332 (e-mail: shyoo@ntu.edu.sg).
} 


\section{Introduction}

"Influence peddling" is one of the important themes in the voluminous literature on corruption (abuse of public office for private gains) ${ }^{1}$ and, the term "revolving doors" has, in turn, been the subject of intense scrutiny in the investigations on influence peddling. The term refers to the lucrative "post-government" employment opportunities (PGEO) that open up for senior bureaucrats often with special expertise. The significant number of transitions from the public to private sector appointments has been documented, ${ }^{2}$ and in many contexts, has been a matter of concern due to the possibility that a public servant (a 'regulator') may be negligent in enforcing the rule of law or in representing public interests for possible future personal gains (employment in a firm, compensation as a lobbyist for an industry...). ${ }^{3}$ Laws on

\footnotetext{
${ }^{1}$ See, for example, Rose-Ackerman (1999) which has some four hundred items in the list of references, and the collection by Elliott (1997).

${ }^{2}$ Almost $51 \%$ of 142 ex-commissioners took related private-sector jobs (Eckert (1981)). Adams (1982) shows that 1,455 former military and 186 civilian employees of the Department of Defense were hired by eight major defense companies during the period 1970-1979, and 31 former employees of NASA were hired by these companies during the period 1974-1979. According to the New York Times (June 18, 2006), among the highest-level executives of the Department of Homeland Security in its beginning years, over two-thirds have moved through the revolving door. For more evidence and descriptions of revolving doors, see Che (1995) and Chapter 11 of Laffont and Tirole (1996).

${ }^{3}$ Here we use the word "regulator" to mean a public servant who "directs or controls by means of applying existing rules and restrictions." The Executive Branch of the United States Government has Departments and Agencies ( Department of Commerce, Environmental Protection Agency, Nuclear Regulatory Commission...) that are, in common parlance at least, "regulatory" bodies. Members of such units with high ranks are typical examples of our "regulators." Note that these bureaucrats or regulators have no law making power (which is the privilege of the Legislative Branch, the Congress). In our model, when a regulator chooses a "higher rate of regulation" s/he is doing a better job in implementing/enforcing the existing laws which were presumably enacted in the first place for the good of the economy/state. We attempt to capture two important ingredients of corruption pointed out by many [following Klitgaard (1988)]: the discretions enjoyed by senior bureaucrats in the interpretation or enforcement of "laws" and the absence of direct accountability. However, our model does not throw light on "influence peddling" by elected members of the Legislative Branch
} 
outright restrictions and/or a "cooling off" period on the passage from the public to the private sector have been enacted in many countries. ${ }^{4}$

In this paper we attempt to develop a formal model with multiple regulators and firms that captures two distinct elements involved in understanding revolving doors, and we refer to these aspects as human capital transfer and collusion building. To elaborate a bit, we observe that it may well be in the interest of a firm to try to acquire expertise in the (possibly complex) laws that are binding given the scope of a firm's activities. The experience that a "high quality" former bureaucrat brings to the firm enables a firm to deal with the legal framework more efficiently and effectively. In other words, the acquisition of a former civil servant can be interpreted as a process of enriching human capital of the firm. High quality bureaucrats, in turn, may choose to send appropriate signals to "strengthen" or "promote" their case. In this context, revolving doors become a natural part of an allocation mechanism that enhances mobility of labor with specialized skills. ${ }^{5}$

On the other hand, firms and regulators may seek to build a collusion that a leniency in the enforcement of current laws (when there is discretion in interpreting the laws or loopholes known to the specialists) enhances the prospects for a future

(for example, promise to introduce or amend laws in exchange for campaign contributions). We wish to thank a referee for raising the issues related to the proper interpretation as well as limited scope of our model.

${ }^{4}$ In the United States, a 1962 act (18 U.S.C. 207(a)) provided for a one-year cooling-off period (Gely and Zardkoohi (2001)). Most countries have similar post-government-employment restrictions. According to a survey by Brezis and Weiss (1997), Canada uses a period of 1.5 or 2 years, the U.K. 2 years, France 5 years, Japan 2 years and Israel 1 year.

${ }^{5}$ Although the revolving-doors topic shares some features with the literatures on regulatory capture as one channel to influence public administrators (see Laffont and Tirole (1996), Dal Bo (2006) and Armstrong and Sappington (2007)) and with "influence-peddling" as one category of corruption (see Elliott (1997)), the human capital aspect makes it distinct from the standard literature on regulatory capture and corruption. Che (1995) introduced the signaling aspect of revolving doors from the human capital perspective first, but in his paper, he uses two separate models: a model with signaling effects and a static model with collusion. 
association. This is troublesome particularly when the future rewards come in the form of a side contract that is not easy to challenge, and an explicit illegal bribe is replaced by a credible understanding in a collusion. ${ }^{6}$

At the cost of significant analytical difficulties, we have chosen to portray the interaction between bureaucrats and firms as one with multiple firms. ${ }^{7}$ This approach is more realistic in many contexts,${ }^{8}$ and also create a broader range of incentives. If there is a single firm, the two incentives of regulators may be in conflict: for signaling one's expertise, a qualified official must regulate stringently, but for collusion building, leniency is called for. With multiple firms, observing stringent regulation for one specific firm no longer guarantees that a regulator is performing his duties: he may be in collusion with the other firm(s).

We start out by introducing a one-stage game with two regulators and two firms. Each regulator is either "qualified" or "unqualified." The firm cannot observe the qualification level or skill of the official but knows the probability of qualification. The case with no PGEO is contrasted with the one where the bureaucrat has PGEO: it is shown that, in the latter case, the qualified bureaucrat regulates more stringently to signal his ability.

Section 3 contains the main analysis in the framework of a repeated game. We show that there exists a wage for the qualified regulator that maximizes the sum of his payoff and the colluding firm's payoff in an equilibrium in which the qualifications of each regulator are revealed through signaling. We call it a collusion-maximizing equilibrium in the infinitely repeated game (CME). Given a CME, the qualified bu-

\footnotetext{
${ }^{6}$ See Martimort (1999) who asserted the need to study collusion among these agents within a framework of "reputation building" through a repeated game. Salant (1995) and Brezis and Weiss (1997) study revolving doors with a repeated game framework, but neither includes the human capital aspect. Moreover, Che (1995) and Salant (1995) find that such mobility could benefit society. Our conclusions open up opposite possibilities.

${ }^{7}$ No previous work on revolving doors or even regulatory capture has noticed how introducing this new environment, multiple firms, can change the behavior of government officials.

${ }^{8}$ For example, none of the major defense companies above in Adams (1982) is a monopoly.
} 
reaucrat manipulates regulation rates for two firms ${ }^{9}$ by regulating the colluding firm leniently for the maximized sum, but regulating the non-colluding firm stringently ${ }^{10}$ for the signaling in order to "compensate" for the lenient regulation toward the colluding firm. ${ }^{11}$ For comparative statics with a CME, it is shown that as the benefits from the collusion increase, this gap between the two firms becomes wider.

Section 4 provides an account of policy implications. The much discussed and widely practiced restrictions on PGEOs have (surprisingly) no effect on regulation rates, and we suggest an alternative policy involving penalties for leniency. Concluding remarks are in Section 5, and all proofs are collected in an appendix.

\section{Model: a one-stage game}

Consider a game with two regulators and two identical firms. ${ }^{12}$ The one-stage game consists of two periods. At the beginning of period 1, the first regulator works for the government when he is "young", and at the end of the period, he is approached by

\footnotetext{
${ }^{9}$ For the inquisitive reader, we note that our second paper on influence peddling, "A Model of Influence Peddling," studies how PGEOs and regulation rates affect the former bureaucrats' wages earned using a first-price, sealed bid auction. However, we do not attempt to summarize the results of our exploration to avoid adding significantly to the length of the present paper. We thank a referee for his interest in this topic.

${ }^{10}$ Often, this type of discrimination is neither verifiable nor detectable. For example, suppose that given its capacity, a tax agent can carry out a small percentage, say twenty percent, of the returns filed by firms. The tax agent can choose two things: select two out of a sample of ten, and examine each case strictly or not. The following is perhaps one of a few cases that only get caught (here, the former officer was rewarded with a bribe instead of a job unlike this paper, which can be regarded as an implicit legal bribe and of course, is harder to catch). "The Busan District Prosecutors' Office arrested former presidential protocol secretary Jeong Yun-jae on bribery and influence-peddling charges for facilitating the bribe of a business man to avoid a tax audit. The business man has admitted to the bribes, and the tax official has also been arrested." (p. 719, International Lawyer Year-in-Review. Vol. 42, No. 2, Summer 2008.)

${ }^{11}$ Otherwise, the unqualified regulator can imitate their strategy.

${ }^{12}$ We choose 2 firms for expository simplicity.
} 
the firms with wage offers. ${ }^{13}$ Accepting one of the offers, he works for the relevant firm in period 2 when he is "old." At the beginning of period 2, the second regulator is born and works for the government when he is young. Hence, in period 1, the first regulator lives as a government official, and in period 2, the first regulator lives as an employee for one of the firms, and the second regulator as a government official. The two firms live for the entire stage.

Each regulator is either qualified $(q=H)$ or unqualified $(q=L)$. The firms cannot directly observe the qualifications level $q \in\{H, L\}$, but they know the likelihood that a regulator is qualified, which is given by $\operatorname{Pr}(q=H)=\theta \in(0,1)$. A qualified regulator acquires regulatory expertise and (or) insider information gained from experience in government, whereas an unqualified regulator has no such advantage over other employees working for non-governmental sectors, and after the first regulator retires, the firms wish to hire the former regulator in order to utilize his or her experience in government.

While working for the government, each regulator chooses a "regulation rate" for each firm, denoted by $\left(r_{1}, r_{2}\right) \in \mathbb{R}_{+}^{2}$. A regulation rate indicates the level of monitoring effort or performance in terms of intensity and/or frequency. The cost of the regulation is denoted by $e_{q}: \mathbb{R}_{+} \rightarrow \mathbb{R}_{+}$for $q \in\{H, L\}$. $e_{q}$ captures the trade-off between expected "penalties" for being lenient in regulating a firm ${ }^{14}$ and "personal costs" from being stringent. $p: \mathbb{R}_{+} \rightarrow \mathbb{R}_{+}$denotes the former, and $c_{q}: \mathbb{R}_{+} \rightarrow \mathbb{R}_{+}$the latter. In other words, a unit increase in the regulation rate has both marginal benefits and costs. Hence, for each $r$, we have $e_{q}(r)=p(r)+c_{q}(r)$. We assume that for each $q, r>0, c_{q}(0)=0, c_{q}^{\prime}(0)=0, c_{q}^{\prime}(r)>0, c_{q}^{\prime \prime}(r)>0$ and $\lim _{r \rightarrow+\infty} c_{q}^{\prime}(r)=+\infty$; for each $r>0, p^{\prime}(0)<0, p^{\prime}(r) \leq 0$ and $p^{\prime \prime}(r) \geq 0 .{ }^{15}$

\footnotetext{
${ }^{13}$ If the former regulator works as a lobbyist outside of the firms, this wages can be interpreted as fees for a contract with him broadly.

${ }^{14}$ The expected penalty consists of the probability that each regulator will be caught by the government and the amount of the penalty.

${ }^{15} p$ is a decreasing function on $r>0$, so after a certain point, it can be constant.
} 
The two firms are in "Bertrand competition," so they earn zero profits if they comply with regulations and laws. However, each firm can obtain positive expected payoff $y_{q}: \mathbb{R}_{+} \rightarrow \mathbb{R}_{+}$by hiring a former regulator and either by not complying with regulations and laws or by exploiting loopholes. $y_{q}$ depends on whether the firm hires a qualified former regulator, that is, ${ }^{16}$

$$
y_{H}(r)>y_{L}(r),
$$

given the same regulation rate $r$ by the incumbent regulator. If the firm hires a qualified former regulator, the firm's payoff is higher than otherwise. In addition, it is reasonable to assume that given each $q, r>0, y_{q}^{\prime}(0)=0, y_{q}^{\prime}(r)<0$, and $y_{q}^{\prime \prime}(r) \leq 0$. The higher the level of monitoring effort the lower the payoff involving explicit or implicit illegal activities, so $y_{q}$ is assumed to be a strictly decreasing function on $r>0$.

Finally, we introduce Spence-Mirrlees property (SMP): for each $r \geq 0$,

$$
c_{L}^{\prime}(r)>c_{H}^{\prime}(r)
$$

which implies that the marginal cost of a qualified regulator is lower than that of an unqualified regulator. ${ }^{17}$ The following Lemma shows that SMP entails that $c_{L}$ dominates $c_{H}$ by the strictly increasing differences and will be useful for proofs in what follows.

Lemma 1 SMP implies that for any $r^{\prime}>r \geq 0$,

$$
e_{L}\left(r^{\prime}\right)-e_{H}\left(r^{\prime}\right)>e_{L}(r)-e_{H}(r) \text {. }
$$

Lemma 1 also means that for any $r>0, e_{L}(r)-e_{H}(r)>0 .{ }^{18}$ A one-stage game consists of two sub-cases: one with no PGEO and the other with PGEO.

\footnotetext{
${ }^{16}$ Hence, a qualified regulator can expect a higher wage only when his or her type is revealed. This assumption is not special in that "qualified" agents always have higher productivity in the signaling literature.

${ }^{17}$ Given the tax agent example in the introduction, the qualified regulator is the one who has "lower" cost of examining a case very hard.

${ }^{18}$ Note that $e_{q}$ is U-shaped for each $q$.
} 


\subsection{Without PGEO}

Without PGEO, neither regulator wishes to exert any effort on regulation different from the cost-minimizing regulation rate given each type. Denote $r_{q}:=$ $\arg \min _{r \in \mathbb{R}_{+}} e_{q}(r)$ for each $q$. Then, a unique $r_{q}>0$ exists. ${ }^{19}$ Lemma 2 shows that without PGEO, the high type's regulation rate is greater than the low type's regulation rate.

Lemma 2 Without $P G E O$, the high type's regulation rate is greater than the low type's regulation rate, that is $r_{H}>r_{L}>0$.

Hence, without PGEO, there is no incentive for either type of the regulators to deviate from $r_{q}$. However, with PGEO, the firms can infer $q$ through the regulation rates.

\section{$2.2 \quad$ With PGEO}

Without PGEO, both the first and second regulators choose $r_{q}$ for $q \in\{H, L\}$. Even with PGEO, the second regulator will behave just as he does without PGEO since in the one-stage game, the second regulator is the last in the time sequence. However, given PGEO, the first regulator wishes to signal his qualifications using the regulation rates for both firms.

(Figure 1 here)

The time line, described in Figure 1, can be seen formally as follows: ${ }^{20}$

Step 1: Nature chooses $q$ for the first regulator.

Step 2: The first regulator chooses regulation rates for both firms $\left(r_{1}, r_{2}\right)$.

\footnotetext{
${ }^{19} p^{\prime \prime}(r) \geq 0$ implies that for any $r>0, p^{\prime}(r) \geq p^{\prime}(0)$. Since $p^{\prime}(r)$ is bounded from below, $\lim _{r \rightarrow+\infty} e_{q}^{\prime}(r)=+\infty$. Hence, $e_{q}^{\prime}(0)<0, \lim _{r \rightarrow+\infty} e_{q}^{\prime}(r)=+\infty$ and $e_{q}^{\prime \prime}(r)>0$.

${ }^{20}$ For a finitely repeated game, it does not matter whether we let Nature decide types of both the first and the second regulator in the beginning, but for an infinitely repeated game in which each period is repeated, this way works better.
} 
Step 3: Given $\left(r_{1}, r_{2}\right)$, the two firms make inferences about the first regulator's qualifications.

Step 4: After the first regulator retires, the two firms simultaneously make wage offers $\left(w_{1}, w_{2}\right)$.

Step 5: The first regulator decides which firm to work for.

Step 6: Nature chooses $q$ for the second regulator.

Step 7: The second regulator determines regulation rates for both firms.

Since Step 7 is the last stage, the second regulator does not have PGEO. It follows from Lemma 2 that a qualified second regulator chooses $r_{H}$, and an unqualified one $r_{L}$

A strategy of firm $i$ is a mapping from $\mathbb{R}_{+}^{2}$ to $\mathbb{R}_{+}$such that

$$
w_{i}=W_{i}\left(r_{1}, r_{2}\right)
$$

Hence, if the type of the first regulator is revealed, the payoffs of firm $i$ when he is qualified and when he is not, respectively, $\operatorname{are}^{21}$

$$
\theta y_{H}\left(r_{H}\right)+(1-\theta) y_{H}\left(r_{L}\right)-w_{i} \text { and } \theta y_{L}\left(r_{H}\right)+(1-\theta) y_{L}\left(r_{L}\right)-w_{i} \text {. }
$$

A strategy of the first regulator is a mapping from $\{H, L\}$ to $\mathbb{R}_{+}^{2}$ such that

$$
\left(r_{1}, r_{2}\right)=\left(R_{1}(q), R_{2}(q)\right)
$$

and the payoff of the first regulator is

$$
\delta \max \left\{w_{1}, w_{2}\right\}-\left[e\left(r_{1}\right)+e\left(r_{2}\right)\right]
$$

where $\delta \in(0,1)$ is the common discount factor for the one period.

A strategy profile in the one-stage game is a sequential equilibrium if for each step in the time line, the strategy of each player is the best response to the other players' strategies, and firms' beliefs about the first regulator's types are updated by

\footnotetext{
${ }^{21}$ Note again that $r_{H}$ and $r_{L}$ are the regulation rates of the second regulator.
} 
Bayes' rule. ${ }^{22}$ A pooling equilibrium is an equilibrium in which both types choose same actions, that is, $\left(R_{1}(H), R_{2}(H)\right)=\left(R_{1}(L), R_{2}(L)\right)$, whereas a separating equilibrium is one in which both types choose different actions, $\left(R_{1}(H), R_{2}(H)\right) \neq$ $\left(R_{1}(L), R_{2}(L)\right)$, so their types are revealed in an equilibrium. We focus on a sequential equilibrium satisfying the intuitive criterion. The intuitive criterion typically eliminates pooling equilibria if the high type can attain a higher payoff by deviating from a pooling equilibrium (see Cho and Kreps (1987) for details). ${ }^{23}$ In what follows, an equilibrium refers to a sequential equilibrium satisfying the intuitive criterion.

An unqualified regulator is one who has not acquired regulatory expertise, so we assume that the firms can hire many employees of the same quality as the unqualified regulator from elsewhere. A perfectly competitive labor market exists in which firms can hire such employees given $\bar{w}_{L}$. Hence, $\bar{w}_{L}$ is the wage that the unqualified regulator can obtain from PGEO in a separating equilibrium. ${ }^{24}$ Let $\theta y_{L}\left(r_{H}\right)+$ $(1-\theta) y_{L}\left(r_{L}\right)-\bar{w}_{L}=0$ so that the payoff of a firm hiring the unqualified former regulator is zero from PGEO in a separating equilibrium. Denote $\bar{w}_{H}:=\theta y_{H}\left(r_{H}\right)+$ $(1-\theta) y_{H}\left(r_{L}\right)$, and since for each $r, y_{H}(r)>y_{L}(r)$, we have $\bar{w}_{H}>\bar{w}_{L}$.

The two firms are identical and make wage offers simultaneously, so $\bar{w}_{H}$ is the wage that the qualified regulator can obtain in a separating equilibrium such as is found in Bertrand competition cases. For a separating equilibrium, we introduce the individual rationality condition for the low type:

$$
\delta \bar{w}_{L}-\left[e_{L}\left(r_{L}\right)+e_{L}\left(r_{L}\right)\right] \geq 0
$$

\footnotetext{
${ }^{22}$ Since there are only two types, the sets of perfect Bayesian equilibria and sequential equilibria coincide (see Fudenberg and Tirole (1991)).

${ }^{23}$ Hence, in the one-stage game, the first regulator is the "sender" of signals, and the two firms are the "receivers."

${ }^{24}$ This will allow us to focus on firms' bidding on the high type, especially in the repeated game later, but the low type still has the incentive to imitate the actions of the high type if he could.
} 
and the incentive compatibility conditions:

$$
\begin{aligned}
\delta \bar{w}_{H}-\left[e_{H}\left(r_{1}\right)+e_{H}\left(r_{2}\right)\right] & \geq \delta \bar{w}_{L}-\left[e_{H}\left(r_{L}\right)+e_{H}\left(r_{L}\right)\right] \\
\delta \bar{w}_{L}-\left[e_{L}\left(r_{L}\right)+e_{L}\left(r_{L}\right)\right] & \geq \delta \bar{w}_{H}-\left[e_{L}\left(r_{1}\right)+e_{L}\left(r_{2}\right)\right] .
\end{aligned}
$$

Consider a maximization problem and denote by $\left(r_{1}^{*}, r_{2}^{*}\right)$ a solution to $(2)$.

$$
\max _{\left(r_{1}, r_{2}\right)} \delta \bar{w}_{H}-\left[e_{H}\left(r_{1}\right)+e_{H}\left(r_{2}\right)\right] \text { subject to }\left(r_{1}, r_{2}\right) \in B
$$

where

$$
B:=\left\{\left(r_{1}, r_{2}\right) \in \mathbb{R}_{+}^{2} \mid \delta \bar{w}_{L}-\left[e_{L}\left(r_{L}\right)+e_{L}\left(r_{L}\right)\right] \geq \delta \bar{w}_{H}-\left[e_{L}\left(r_{1}\right)+e_{L}\left(r_{2}\right)\right]\right\}
$$

Lemma 3 establishes that the set of equilibrium strategies and the set of solutions to (2) coincide.

Lemma 3 If (IR) is satisfied,

(i) no pooling equilibrium exists.

(ii) the set of equilibrium strategies is the same as the set of solutions to (2).

We show that with PGEO in a one-stage game, an equilibrium exists and $\left(r_{1}^{*}, r_{2}^{*}\right)$ is at least as large as the high type's regulation rate without PGEO. ${ }^{25}$

Proposition 1 If (IR) is satisfied, with PGEO in a one-stage game,

(i) an equilibrium exists.

(ii) $r_{1}^{*} \geq r_{H}$ and $r_{2}^{*} \geq r_{H}$.

Hence, the existence of PGEO in a one-stage game is beneficial to society since the qualified regulator voluntarily wishes to increase the regulation rates for both

\footnotetext{
${ }^{25}$ Since the incentive compatibility condition for the low type is a strictly convex function of $r$, we have to utilize SMP and necessary conditions of the maximization problem to characterize the solution to (2). Hence, this problem is not as trivial as it might look.
} 
firms in order to deter the unqualified regulator from imitating the qualified regulator's strategy, and this result echoes Che (1995). The following Corollary shows (i) that if $\left(r_{H}, r_{H}\right) \notin B$, then, the qualified regulator strictly increases the regulation rates for both firms with PGEO, and (ii) a sufficient condition for the uniqueness. ${ }^{26}$

Corollary 1 Suppose that (IR) is satisfied.

(i) If $\left(r_{H}, r_{H}\right) \notin B, r_{1}^{*}>r_{H}$ and $r_{2}^{*}>r_{H}$,

(ii) If $e_{L}^{\prime}(r) / e_{H}^{\prime}(r)$ is strictly monotone on $\left(r_{H},+\infty\right), r_{1}^{*}=r_{2}^{*}$ and the equilibrium regulation profile is unique.

In a one-stage game, with PGEO, the qualified regulators have no incentive other than to signal their qualifications through the regulation rates, which leads to greater regulation rates. On the other hand, the firms do not have strong incentive not to comply with regulations and laws since they obtain zero profits either way. However, in an infinitely repeated game, a sequence of qualified regulators and a firm can collude in order to attain higher payoffs.

\section{Model: a repeated game}

Consider an infinitely repeated game in which there is a sequence of regulators, and in each period, two regulators and two firms play the one-stage game described in the previous section. Hence, each regulator lives for two periods, and the firms live infinitely, so the regulators are "short-run players," and the two firms are "long-run players." 27 At the beginning of period $t$ for each $t=1,2,3 \ldots$, the $t$ th regulator works

\footnotetext{
${ }^{26}$ Since the choice set is not convex, without any additional structure on $e_{q}$, it is not clear whether the regulation rates for both firms are the same in an equilibrium, and whether the solution to (11) is unique.

${ }^{27}$ For models with short-run players, see Fudenberg, Kreps and Maskin (1990) and Kreps (1990). In addition, this is not a repeated game in which the same normal form game is repeated over time as standard repeated games or supergames are defined, but a repeated game in which the same
} 
for the government when he is young, and at the end of the period, he is approached by the firms with wage offers. Accepting one of the offers, he works for the relevant firm in period $t+1$ when he is old. At the beginning of period $t+1$, the $(t+1)$ th regulator works for the government when he is young. Hence, except for period 1, for each period $t$, the $(t-1)$ th regulator lives as an employee for one of the firms, and the $t$ th regulator lives as a government official.

Let $q(t)$ denote the type of the regulator in period $t(t=1,2,3, \ldots)$. Only the regulator in period $t$ knows the realized value of $q(t)$, and the other players know that $q(t)$ is independently and identically drawn with probability $\operatorname{Pr}(q(t)=H)=$ $\theta \in(0,1)$. Similarly, action variables in period $t$ can be written by $\left(w_{1}(t), w_{2}(t)\right)$ and $\left(r_{1}(t), r_{2}(t)\right)$. The regulation rates and the wages paid to each regulator are publicly observable to all players in every period afterward. Denote the history up to $t$ by $H(t):=\left\{w_{1}(1), w_{2}(1), r_{1}(1), r_{2}(1), \ldots, w_{1}(t), w_{2}(t), r_{1}(t), r_{2}(t)\right\}$. A strategy of each player in period $t$ is a mapping from his or her information about the past history of the game $H(t-1)$ to his or her actions. In particular, a regulator's strategy in period $t$ is a mapping from $H(t-1) \times\{H, L\}$ to $\mathbb{R}_{+}^{2}$.

In the repeated game, we study types of collusion between the sequence of regulators and firms such that qualified regulators collude with one of the firms. We label the firms $(C, N)$ instead of $(1,2)$ to indicate $C$ as a firm under collusion with the sequence of qualified regulators in the repeated game, and $r_{C}$ denotes the regulation rate for the colluding firm and $r_{N}$ that for the non-colluding firm. In contrast to the one-stage game, there are still many sequential equilibria satisfying the intuitive criterion with collusion in the repeated game, so we select one in Pareto-frontier among them by maximizing the sum of the qualified regulator's one-period payoff and the colluding firm's one-period payoff. ${ }^{28}$

\footnotetext{
extensive form game is "repeated" over time that is a special type of dynamic games. In particular, we invite readers to see the simple example in the first paragraph at page 555 in Fudenberg, Kreps and Maskin (1990).

${ }^{28}$ Hence, we look for stationary equilibrium strategies in which players choose same actions in each period on the equilibrium path.
} 
Denote by $u_{C}$ and $u_{H}$ the colluding firm's one-period expected payoff from hiring a former regulator and the qualified regulator's expected payoff, respectively: ${ }^{29}$

$$
\begin{aligned}
& u_{C}\left(w_{H}, r_{C}\right)=\theta\left[\theta y_{H}\left(r_{C}\right)+(1-\theta) y_{H}\left(r_{L}\right)-w_{H}\right]+(1-\theta)\left[\theta y_{L}\left(r_{C}\right)+(1-\theta) y_{L}\left(r_{L}\right)-\bar{w}_{L}\right], \\
& u_{H}\left(r_{C}, r_{N}, w_{H}\right)=\theta\left\{\delta w_{H}-\left[e_{H}\left(r_{C}\right)+e_{H}\left(r_{N}\right)\right]\right\} .
\end{aligned}
$$

Consider a maximization problem and denote by $\mathbf{r}^{*}:=\left(r_{C}^{*}, r_{N}^{*}\right)$ a solution to (4). ${ }^{30}$

$$
\max _{\left(r_{C}, r_{N}\right)} u_{C}\left(w_{H}, r_{C}\right)+u_{H}\left(r_{C}, r_{N}, w_{H}\right) \text { subject to }\left(r_{C}, r_{N}\right) \in \mathbf{B}\left(w_{H}\right),
$$

where

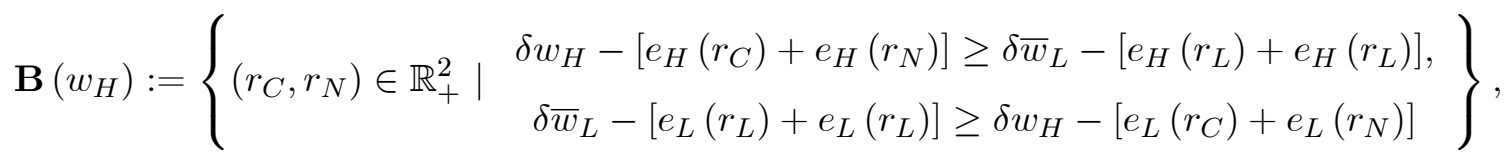

$$
\begin{aligned}
& \text { and } \\
& w_{H} \in \Pi:=\left\{w \in \mathbb{R} \mid w \geq \bar{w}_{L}\right\} .
\end{aligned}
$$

We construct the following grim strategy for the repeated game. Under collusion, each qualified regulator exercises the regulation rate $\left(r_{C}^{*}, r_{N}^{*}\right)$, and the colluding firm hires a former qualified regulator at the total wage $\left(w_{H}^{\dagger}+w_{H}^{\ddagger}\right)$ in which $w_{H}^{\dagger}$ is a wage offer made before he or she works for the firm, as in the one-stage game, and $w_{H}^{\ddagger}$ is the wage paid after he works for the firm and turns out qualified. ${ }^{31}$ Define

${ }^{29}$ Note that $w_{H}$ is a transfer between the colluding firm and the high type.

${ }^{30} \mathrm{As}$ in the one-stage game, the objective function is strictly concave, and the choice set is nonconvex. Lemma 3 also implies that if $w_{H} \geq \bar{w}_{L}$, there exists $\left(r_{1}^{\prime}, r_{2}^{\prime}\right) \in \mathbb{R}_{+}^{2}$ satisfying ICs in (1). Hence, for all $w_{H} \in \Pi, \mathbf{B}\left(w_{H}\right)$ is not empty.

${ }^{31} w_{H}^{\ddagger}$ can be considered a bonus, and we assume here that each regulator's type is revealed after he or she works for a firm. This assumption is not idiosyncratic in the signaling literature in the sense that the classical signaling paper, Spence (1973), assumed it to capture consistency before a formal equilibrium concept was introduced. Of course, we can have the same assumption in the one stage, but it will not affect the results there at all because of the equilibrium concept that we adopt, a sequential equilibrium with intuitive criterion. Notice also that this does not mean that the signaling aspect disappears in the repeated game. The two firms should make wage offers to regulators before they start working for the firms as in the one-stage game, and their types can be revealed only through signaling. 
a defection of the qualified regulator as adopting $r_{C}>r_{C}^{*}$, and a defection of the colluding firm as employing a wage less than $\left(w_{H}^{\dagger}+w_{H}^{\ddagger}\right)$. If and when the qualified regulators and the colluding firm learn that a defection has taken place, they apply the equilibrium strategies in the one-stage game thereafter.

Let $w_{H}^{N}$ denote the maximum bid that the non-colluding firm can make and let $u_{N}\left(w_{H}^{N}, r_{N}\right)$ be the non-colluding firm's one-period expected payoff. Then, $w_{H}^{N}$ satisfies $u_{N}\left(w_{H}^{N}, r_{N}^{*}\right)=0$. If ${ }^{32}$

$$
\begin{aligned}
& \text { (a) } \exists w_{H}^{\dagger} \in \Pi \text { s.t. } u_{C}\left(w_{H}^{\dagger}, r_{C}^{*}\right)+u_{H}\left(r_{C}^{*}, r_{N}^{*}, w_{H}^{\dagger}\right)>u_{H}\left(r_{1}^{*}, r_{2}^{*}, \bar{w}_{H}\right), \\
& \text { (b) } r_{C}^{*}<r_{N}^{*},
\end{aligned}
$$

we can find a $w_{H}^{\ddagger}$ such that ${ }^{33}$

$$
\begin{array}{cl}
u_{H}\left(r_{C}^{*}, r_{N}^{*}, w_{H}^{\dagger}\right)+\theta \delta w_{H}^{\ddagger}>u_{H}\left(r_{1}^{*}, r_{2}^{*}, \bar{w}_{H}\right) & (\mathrm{H}), \\
u_{C}\left(w_{H}^{\dagger}, r_{C}^{*}\right)-\theta w_{H}^{\ddagger}>0 & (\mathrm{C}), \\
w_{H}^{\dagger}+w_{H}^{\ddagger}>w_{H}^{N} & (\mathrm{~B}) .
\end{array}
$$

$w_{H}^{\dagger}$ is related to how to make a bigger "pie" for both, and $w_{H}^{\ddagger}$ is related to how to divide the pie in order to guarantee that each of them ends up with a higher payoff in the repeated game as in $(\mathrm{H})$ and $(\mathrm{C})$. Given the equilibrium, the colluding firm's bid for the qualified regulator is higher than the non-colluding firm's, so the colluding firm can secure employment of the qualified as in (B). The colluding firm can make a higher bid in an equilibrium since each firm's payoff is a strictly decreasing function of regulation rates, and $r_{C}^{*}<r_{N}^{*} \cdot{ }^{34}$

\footnotetext{
${ }^{32}$ In words, (a) says that the maximum expected payoff from (4) is greater than the maximum payoff for both in the one-stage game.

${ }^{33}$ Note that each firm's payoff in the one-stage game is zero.

${ }^{34}$ The reason that collusion with only one firm is taking place on the equilibrium path is that the colluding firm can make a higher bid in every period. One may wonder why then the other firm should remain silent. Of course, the non-colluding firm has a greater "incentive" to start colluding with a sequence of regulators, but it does not have such "capacity," that is, it cannot make a higher bid since its payoff is always lower than the colluding firm's from the beginning (if borrowing is not
} 
Then, if $\delta$ is sufficiently close to 1 , as usual, a collusive equilibrium exists. Define $f: \mathbb{R}_{+} \rightarrow \mathbb{R}_{+}$as $f\left(r_{C}\right):=\left[\theta y_{H}\left(r_{C}\right)+(1-\theta) y_{L}\left(r_{C}\right)\right] . \quad f$ is the colluding firm's expected payoff from hiring a former regulator. Then, (4) can be rewritten as

$$
\max _{\left(r_{C}, r_{N}\right)} f\left(r_{C}\right)-\left[e_{H}\left(r_{C}\right)+e_{H}\left(r_{N}\right)\right] \text { subject to }\left(r_{C}, r_{N}\right) \in \mathbf{B}\left(w_{H}\right) .
$$

First, we show that a solution $\mathbf{r}^{*}$ to the maximization problem (6) exists, and characterize it.

Proposition 2 Given any $w_{H} \in \Pi$,

(i) there exists a solution $\mathbf{r}^{*}$ to the maximization problem (6).

(ii) $r_{N}^{*} \geq r_{H}$ and $r_{N}^{*}>r_{C}^{*}>0$.

We say that a collusion-maximizing equilibrium in the infinitely repeated game $(\mathrm{CME})$ is $\left(\mathbf{r}^{*}, w_{H}^{\dagger}\right)$ if $\left(\mathbf{r}^{*}, w_{H}^{\dagger}\right)$ satisfies $(a)$ and $(b)$ in $(5)$.

Definition $1\left(\mathbf{r}^{*}, w_{H}^{\dagger}\right)$ is a CME if $\left(\mathbf{r}^{*}, w_{H}^{\dagger}\right)$ satisfies $(a)$ and $(b)$ in (5).

The solution $\mathbf{r}^{*}$ to $(6)$ is a function of $w_{H}$, and the natural candidate for $w_{H}^{\dagger}$ is the one that maximizes the sum of payoffs, which is denoted by $w_{H}^{*}$. Hence, if $\left(\mathbf{r}^{*}\left(w_{H}^{*}\right), w_{H}^{*}\right)$ satisfies (a) and (b) in (5), we can show the existence of a CME.

Proposition 3 If (IR) is satisfied, there exists a $C M E\left(\mathbf{r}^{*}\left(w_{H}^{*}\right), w_{H}^{*}\right)$.

Hence, given a $\operatorname{CME}\left(\mathbf{r}^{*}\left(w_{H}^{*}\right), w_{H}^{*}\right)$, the qualified bureaucrat regulates the two firms with different rates: for the collusion, the qualified bureaucrat must regulate the colluding firm leniently, but for the signaling in a separating equilibrium, he must

allowed). We could think of other types of equilibria, e.g. giving alternating favors to two firms, but it is not difficult to see that favoring only one firm (or punishing only one firm) makes their pie biggest. 
regulate the non-colluding firm stringently in order to compensate for the lenient regulation toward the colluding firm. ${ }^{35}$

Assume that $e_{H}^{\prime}$ dominates $e_{L}^{\prime}$ by the strictly log-increasing differences. ${ }^{36}$ This is equivalent to

$$
\frac{e_{H}^{\prime \prime}(r)}{e_{H}^{\prime}(r)}>\frac{e_{L}^{\prime \prime}(r)}{e_{L}^{\prime}(r)} \text { for } r>r_{H} .
$$

The first result of Proposition 4 establishes that a collusion-maximizing profile $\left(\mathbf{r}^{*}\left(w_{H}^{*}\right), w_{H}^{*}\right)$ results in a set of regulation rates $\left(r_{C}^{*}, r_{N}^{*}\right)$ such that the regulation rate for the colluding firm is even lower than the unqualified official's regulation rate without PGEO. ${ }^{37}$

Models with a parameter other than $w_{H}$ will be analyzed in the comparative statics below and in the next section. Denote $\operatorname{by}^{38} \mathbf{r}^{*}\left(w_{H}, \tau\right):=\left(r_{C}^{*}\left(w_{H}, \tau\right), r_{N}^{*}\left(w_{H}, \tau\right)\right)$ a solution to the collusion-maximization problem given $w_{H}$ and a parameter $\tau$. The second and third results of Proposition 4 imply that given a $\operatorname{CME}\left(\mathbf{r}^{*}\left(w_{H}^{*}, \tau\right), w_{H}^{*}\right)$, if at least one of constraints is binding, the changes in a parameter $\tau$ have two effects

\footnotetext{
${ }^{35}$ Given the tax agent example in the introduction, the lenient regulation means not to choose a firm under collusion for tax audit or not to examine the firm hard if it has to audit it, and the stringent one means the opposite. Since the regulator can choose a different firm for the stringent regulation "in turn," it is hard for the other firm(s) to argue about it or to bring the case to the court.

${ }^{36}$ We wish to apply a Envelope Theorem to obtain the second result in Proposition 4. The difficulty with it is, again, the fact that the choice set is not convex, so we cannot apply "conventional" Envelope Theorems. However, Milgrom and Segal (2002) show that if a value function is differentiable, we can use the traditional Envelope formula, so we want to prove that $r^{*}$ is differentiable using the Implicit Function Theorem, and (7) is a sufficient condition for that. Let's take a simple example satisfying the conditions of $e_{q}$ by assuming that $p(r)=-r, c_{H}(r)=r^{2} / 2$ and $c_{L}(r)=r^{2}$. It follows that $e_{H}^{\prime \prime}(r) / e_{H}^{\prime}(r)=1 /(-1+r)$ and $e_{L}^{\prime \prime}(r) / e_{L}^{\prime}(r)=2 /(-1+2 r)$, which is clearly the case with (7).

${ }^{37}$ If the negative social effect of lenient-regulations is a strictly convex function, the total effect of these distorted regulations from collusion on social welfare will be negative.

${ }^{38}$ We could use this general form from the beginning of this section, but it will make the notations more complicated. For the sake of simplicity, we assume that $r^{*}$ is a function of $\left(w_{H}, \tau\right)$ in what follows.
} 
on the changes in the solution $\mathbf{r}^{*}\left(w_{H}^{*}(\tau), \tau\right)$ of the collusion maximization: a direct effect and an indirect effect through $w_{H}^{*}$.

Proposition 4 If (IR) and (7) are satisfied, given a $C M E\left(\mathbf{r}^{*}\left(w_{H}^{*}, \tau\right), w_{H}^{*}\right)$,

(i) $r_{C}^{*}<r_{L}$ and $r_{N}^{*}>r_{H}$.

(ii) $\mathbf{r}^{*}$ is a unique function of $\left(w_{H}, \tau\right)$ and differentiable.

(iii) $w_{H}^{*}$ is a unique function of $\tau$ and differentiable.

For comparative statics, with a slight abuse of notation, we rewrite $f(r)$ as $f(r, s)$ where $s \in S$ is a parameter with $S \subset \mathbb{R}$ and assume that $f$ is differentiable. ${ }^{39}$ Let

$$
\frac{\partial^{2} f(r, s)}{\partial r \partial s}<0
$$

meaning that the marginal product of regulation is a strictly decreasing function of $s$. The second main result of this section establishes that if the benefits from collusion increase, to maximize the sum of the payoffs under collusion, each qualified regulator strictly decreases the regulation rate for the colluding firm. However, at the same time, in order to deter each unqualified regulator from imitating the qualified regulator's strategy, each qualified regulator strictly increases the regulation rate for the non-colluding firm.

Proposition 5 If (IR) and(7) are satisfied, given a $C M E\left(\mathbf{r}^{*}\left(w_{H}^{*}, s\right), w_{H}^{*}\right)$, for any pair $s^{\prime}>s$,

$$
r_{C}^{*}\left(w_{H}^{*}\left(s^{\prime}\right), s^{\prime}\right)<r_{C}^{*}\left(w_{H}^{*}(s), s\right) \text { and } r_{N}^{*}\left(w_{H}^{*}\left(s^{\prime}\right), s^{\prime}\right)>r_{N}^{*}\left(w_{H}^{*}(s), s\right)
$$

This parameterization is quite general. For example, one special case of it is when $s$ is $\theta$, the likelihood that a regulator is qualified. Then, given $y_{q}^{\prime}<0$, if SMP between $y_{H}$ and $y_{L}$ is assumed such that for each $r, y_{H}^{\prime}(r)>y_{L}^{\prime}(r)$, we have

\footnotetext{
${ }^{39}$ The authors learned this way of parameterizing functions from Quah (2007) although his general results cannot be applied here since the choice set in this paper is not convex.
} 
$\partial^{2} f(r, s) / \partial r \partial \theta>0$, which is exactly the opposite case of Proposition 5. Hence, as the likelihood that a regulator is qualified strictly increases, the benefit from collusion strictly decreases. If (IR) and (7) are satisfied, given a $\mathrm{CME}\left(r^{*}\left(w_{H}^{*}, \theta\right), w_{H}^{*}\right)$, for any pair $\theta^{\prime}>\theta, r_{C}^{*}\left(w_{H}^{*}\left(\theta^{\prime}\right), \theta^{\prime}\right)>r_{C}^{*}\left(w_{H}^{*}(\theta), \theta\right)$ and $r_{N}^{*}\left(w_{H}^{*}\left(\theta^{\prime}\right), \theta^{\prime}\right)<r_{N}^{*}\left(w_{H}^{*}(\theta), \theta\right)$.

\section{Policy Implications}

Until now, policies regarding revolving doors have focused exclusively on postgovernment-employment restrictions. Proposition 6 studies the effect of the number of "cooling-off" periods, and we show that post-government-employment restrictions are not effective policies; not to mention the possibility that such restrictions deprive former government officials of the right to take jobs that require their skills and experience.

Proposition 6 If (IR) and(7) are satisfied, given a $C M E\left(\mathbf{r}^{*}\left(w_{H}^{*}, \delta\right), w_{H}^{*}\right)$, postgovernment-employment restrictions have no effect on regulation rates for both firms, that is, for any $n \geq 2$,

$$
r_{C}^{*}\left(w_{H}^{*}\left(\delta^{n}\right), \delta^{n}\right)=r_{C}^{*}\left(w_{H}^{*}(\delta), \delta\right) \text { and } r_{N}^{*}\left(w_{H}^{*}\left(\delta^{n}\right), \delta^{n}\right)=r_{N}^{*}\left(w_{H}^{*}(\delta), \delta\right) .
$$

Although the direct effect of the changes in $\delta$ on $r_{C}^{*}$ is negative, and the direct effect of the changes in $\delta$ on $r_{N}^{*}$ is positive, their net effects are zero because of the opposite indirect effects. As long as the collusion-maximization in the repeated game is sustained, the optimal regulation rates will not be affected by the changes in the discount factor. ${ }^{40}$

Now, we suggest an alternative policy to induce each qualified regulator to be more stringent in regulating the firm that is in collusion with a sequence of qualified

\footnotetext{
${ }^{40}$ Recall (IR) with $n$ restricted periods: $\delta^{n} \bar{w}_{L}-\left[e_{L}\left(r_{L}\right)+e_{L}\left(r_{L}\right)\right] \geq 0$. If $\delta^{n}$ is so small that (IR) is not satisfied, of course, the result is not valid any more. This claim may be seen too strong since we are assuming that the knowledge that the regulators gained from government does not deteriorate over time.
} 
regulators. We modify $p(r)$ as $p(r, t)$ where $t \in T$ is a parameter with $T \subset \mathbb{R}$, and let $p$ be differentiable. Let

$$
\frac{\partial^{2} p(r, t)}{\partial r \partial t}=d<0
$$

which implies that as $t$ strictly increases, the magnitude of the marginal expected penalty of the regulation rate strictly increases. ${ }^{41}$ Proposition 7 establishes that as the magnitude of the marginal expected penalty strictly increases, the regulation rate for the colluding firm strictly increases, and the regulation rate for the noncolluding firm strictly decreases.

Proposition 7 If (IR) and( 7$)$ are satisfied, given a $C M E\left(\mathbf{r}^{*}\left(w_{H}^{*}, t\right), w_{H}^{*}\right)$, it follows from the policy (8) that for any pair $t^{\prime}>t$,

$$
r_{C}^{*}\left(w_{H}^{*}\left(t^{\prime}\right), t^{\prime}\right)>r_{C}^{*}\left(w_{H}^{*}(t), t\right) \text { and } r_{N}^{*}\left(w_{H}^{*}\left(t^{\prime}\right), t^{\prime}\right)<r_{N}^{*}\left(w_{H}^{*}(t), t\right) .
$$

\section{Concluding Remarks}

In our exposition, we have attempted to synthesize three themes: mobility of human capital, signaling and collusion in a framework with a sequence of regulators and two firms, and we are not aware of any paper that incorporates all these, but this formal model cannot capture the variety of contexts and connotations of "influence peddling" that one encounters in the vast (informal) literature.

Although the paper builds on well-known equilibrium concepts, we should perhaps stress that our analysis was still challenging at various steps and needed careful reasoning for the following reasons. Observe that the qualified regulator's payoff maximization in (2) and the collusion maximization in (4) are constrained by a nonconvex choice set, and this non-convexity is caused by the incentive compatibility condition of the low type. Hence, all the "standard" tools for optimization are not sufficient to derive important results in this paper.

\footnotetext{
${ }^{41}$ Note that the marginal expected penalty of the regulation rate is negative.
} 
The comparative statics results can be obtained under (7), and when there are $n \geq 3$ multiple firms, the analysis of this paper can be extended either to the case in which each bureaucrat chooses regulation rates after selecting 2 firms out of $n$ firms such as the example in the introduction, or to the case in which each bureaucrat regulates one firm leniently and all the other firms equally stringently, by substituting $(n-1) e_{q}\left(r_{N}\right)$ and $(n-1) e_{q}\left(r_{L}\right)$ for the $n-1$ non-colluding firms given each type of $\{H, L\}$ into (4), but not to the other general settings.

\section{Appendix: Proofs}

Proof of Lemma 1. Denote $\Delta c(r):=c_{L}(r)-c_{H}(r)$. Then, SMP entails $\Delta c^{\prime}(a)>0$ for all $a>0$. By the Mean Value Theorem, given $r^{\prime}>r \geq 0$, there exists $a \in\left(r, r^{\prime}\right)$ such that $\Delta c^{\prime}(a)=\left(\Delta c\left(r^{\prime}\right)-\Delta c(r)\right) /\left(r^{\prime}-r\right)$. It follows from $\Delta c^{\prime}(a)>0$ that $\Delta c\left(r^{\prime}\right)>\Delta c(r)$, which shows the result.

Proof of Lemma 2. First, we have $r_{H} \neq r_{L}$ since otherwise for some $r, e_{H}^{\prime}(r)=$ $e_{L}^{\prime}(r)=0$ implying $c_{H}^{\prime}(r)=c_{L}^{\prime}(r)$, which contradicts SMP. Then, it follows from the definition of $r_{q}$ that $e_{H}\left(r_{H}\right)<e_{H}\left(r_{L}\right)$ and $e_{L}\left(r_{L}\right)<e_{L}\left(r_{H}\right)$. Summing the two inequalities above, $e_{L}\left(r_{H}\right)-e_{H}\left(r_{H}\right)>e_{L}\left(r_{L}\right)-e_{H}\left(r_{L}\right)$. Hence, if $r_{L}>r_{H}$, we have a contradiction with Lemma 1. Alternatively, we can simply use the result in Milgrom and Shannon (1994).

Proof of Lemma 3. (i) Suppose that there is a pooling equilibrium satisfying the intuitive criterion. Then, the wage that each type can obtain is $w:=\theta \bar{w}_{H}+(1-\theta) \bar{w}_{L}$. It is sufficient to demonstrate that the high type can attain a higher payoff by deviating from the pooling equilibrium, and the low type cannot imitate the action of the high type. In other words, we show that given any $\left(r_{1}, r_{2}\right) \in \mathbb{R}_{+}^{2}$, there exists $\left(r_{1}^{\prime}, r_{2}^{\prime}\right) \in \mathbb{R}_{+}^{2}$ such that

$$
\begin{aligned}
\delta \bar{w}_{H}-\left[e_{H}\left(r_{1}^{\prime}\right)+e_{H}\left(r_{2}^{\prime}\right)\right] & >\delta w-\left[e_{H}\left(r_{1}\right)+e_{H}\left(r_{2}\right)\right], \\
\delta w-\left[e_{L}\left(r_{1}\right)+e_{L}\left(r_{2}\right)\right] & >\delta \bar{w}_{H}-\left[e_{L}\left(r_{1}^{\prime}\right)+e_{L}\left(r_{2}^{\prime}\right)\right] .
\end{aligned}
$$

Since $\bar{w}_{H}>w$ and $\lim _{r \rightarrow+\infty} e_{q}^{\prime}(r)=+\infty$ implies $\lim _{r \rightarrow+\infty} e_{q}(r)=+\infty$, there exists 
$\left(r_{1}^{\prime \prime}, r_{2}^{\prime \prime}\right)>\left(r_{1}, r_{2}\right)$ and $\left(r_{1}^{\prime \prime}, r_{2}^{\prime \prime}\right)>\left(r_{L}, r_{L}\right)$ such that

$$
\delta w-\left[e_{L}\left(r_{1}\right)+e_{L}\left(r_{2}\right)\right]=\delta \bar{w}_{H}-\left[e_{L}\left(r_{1}^{\prime \prime}\right)+e_{L}\left(r_{2}^{\prime \prime}\right)\right] .
$$

It follows from SMP that

$$
\left[e_{L}\left(r_{1}^{\prime \prime}\right)-e_{H}\left(r_{1}^{\prime \prime}\right)\right]+\left[e_{L}\left(r_{2}^{\prime \prime}\right)-e_{H}\left(r_{2}^{\prime \prime}\right)\right]>\left[e_{L}\left(r_{1}\right)-e_{H}\left(r_{1}\right)\right]+\left[e_{L}\left(r_{2}\right)-e_{H}\left(r_{2}\right)\right] .
$$

Then,

$\left[e_{L}\left(r_{1}^{\prime \prime}\right)-e_{H}\left(r_{1}^{\prime \prime}\right)\right]+\left[e_{L}\left(r_{2}^{\prime \prime}\right)-e_{H}\left(r_{2}^{\prime \prime}\right)\right]+\left[\delta \bar{w}_{H}-\delta w\right]>\left[\delta \bar{w}_{H}-\delta w\right]+\left[e_{L}\left(r_{1}\right)-e_{H}\left(r_{1}\right)\right]+\left[e_{L}\left(r_{2}\right)-e_{H}\left(r_{2}\right)\right]$.

By (10),

$$
\delta \bar{w}_{H}-\left[e_{H}\left(r_{1}^{\prime \prime}\right)+e_{H}\left(r_{2}^{\prime \prime}\right)\right]>\delta w-\left[e_{H}\left(r_{1}\right)+e_{H}\left(r_{2}\right)\right]
$$

Since $e_{q}$ is continuous, there exists $\left(r_{1}^{\prime}, r_{2}^{\prime}\right) \in \mathbb{R}_{+}^{2}$ such that $\left(r_{1}^{\prime}, r_{2}^{\prime}\right)>\left(r_{1}^{\prime \prime}, r_{2}^{\prime \prime}\right)$ and $\left(r_{1}^{\prime}, r_{2}^{\prime}\right)$ is sufficiently close to $\left(r_{1}^{\prime \prime}, r_{2}^{\prime \prime}\right)$. Then, $\left(r_{1}^{\prime}, r_{2}^{\prime}\right)$ satisfies (9).

(ii) Consider the following maximization problem and denote by $\left(r_{1}^{\dagger}, r_{2}^{\dagger}\right)$ the solution to (11).

$$
\max _{\left(r_{1}, r_{2}\right) \in \mathbb{R}_{+}^{2}} \delta \bar{w}_{H}-\left[e_{H}\left(r_{1}\right)+e_{H}\left(r_{2}\right)\right] \text { subject to two ICs in (1). }
$$

Note that the individual rationality condition of the high type results from (IR).

$$
\delta \bar{w}_{H}-\left[e_{H}\left(r_{1}\right)+e_{H}\left(r_{2}\right)\right] \geq \delta \bar{w}_{L}-\left[e_{H}\left(r_{L}\right)+e_{H}\left(r_{L}\right)\right]>\delta \bar{w}_{L}-\left[e_{L}\left(r_{L}\right)+e_{L}\left(r_{L}\right)\right] \geq 0 .
$$

Part 1. If $\left(r_{1}, r_{2}\right)$ is a separating equilibrium satisfying the intuitive criterion, then $\left(r_{1}, r_{2}\right)$ is a solution to (11). Suppose that $\left(r_{1}, r_{2}\right)$ is a separating equilibrium satisfying the intuitive criterion and $\left(r_{1}, r_{2}\right) \neq\left(r_{1}^{\dagger}, r_{2}^{\dagger}\right)$, which implies

$$
\begin{aligned}
\delta \bar{w}_{H}-\left[e_{H}\left(r_{1}^{\dagger}\right)+e_{H}\left(r_{2}^{\dagger}\right)\right] & >\delta \bar{w}_{H}-\left[e_{H}\left(r_{1}\right)+e_{H}\left(r_{2}\right)\right], \\
\delta \bar{w}_{L}-\left[e_{L}\left(r_{L}\right)+e_{L}\left(r_{L}\right)\right] & \geq \delta \bar{w}_{H}-\left[e_{L}\left(r_{1}^{\dagger}\right)+e_{L}\left(r_{2}^{\dagger}\right)\right] .
\end{aligned}
$$

By adding two ICs in (1),

$$
\left[e_{L}\left(r_{1}\right)-e_{H}\left(r_{1}\right)\right]+\left[e_{L}\left(r_{2}\right)-e_{H}\left(r_{2}\right)\right] \geq\left[e_{L}\left(r_{L}\right)-e_{H}\left(r_{L}\right)\right]+\left[e_{L}\left(r_{L}\right)-e_{H}\left(r_{L}\right)\right]
$$

It follows from SMP that at least one of $\left(r_{1}, r_{2}\right)$ is greater than or equal to $r_{L}$. WLOG, $r_{1}^{\dagger} \geq r_{L}$. Since $\lim _{r \rightarrow+\infty} e_{q}(r)=+\infty$, there exists $r_{1}^{\prime}>r_{H}$ such that $e_{H}\left(r_{1}^{\prime}\right)>e_{H}\left(r_{1}^{\dagger}\right)$ and

$$
\delta \bar{w}_{H}-\left[e_{H}\left(r_{1}^{\dagger}\right)+e_{H}\left(r_{2}^{\dagger}\right)\right]>\delta \bar{w}_{H}-\left[e_{H}\left(r_{1}^{\prime}\right)+e_{H}\left(r_{2}^{\dagger}\right)\right]>\delta \bar{w}_{H}-\left[e_{H}\left(r_{1}\right)+e_{H}\left(r_{2}\right)\right] .
$$


$e_{L}$ is strictly increasing on $\left[r_{L},+\infty\right)$, so

$$
\delta \bar{w}_{L}-\left[e_{L}\left(r_{L}\right)+e_{L}\left(r_{L}\right)\right] \geq \delta \bar{w}_{H}-\left[e_{L}\left(r_{1}^{\dagger}\right)+e_{L}\left(r_{2}^{\dagger}\right)\right]>\delta \bar{w}_{H}-\left[e_{L}\left(r_{1}^{\prime}\right)+e_{L}\left(r_{2}^{\dagger}\right)\right] .
$$

Hence, the existence of $\left(r_{1}^{\prime}, r_{2}^{\dagger}\right)$ contradicts the intuitive criterion.

Part 2. If $\left(r_{1}, r_{2}\right)$ is a solution to $(11)$, then $\left(r_{1}, r_{2}\right)$ is a separating equilibrium satisfying the intuitive criterion. Suppose that $\left(r_{1}, r_{2}\right)$ does not satisfy the intuitive criterion. Then, there exists $\left(r_{1}^{\prime}, r_{2}^{\prime}\right) \in \mathbb{R}_{+}^{2}$ such that

$$
\begin{aligned}
\delta \bar{w}_{H}-\left[e_{H}\left(r_{1}^{\prime}\right)+e_{H}\left(r_{2}^{\prime}\right)\right] & >\delta \bar{w}_{H}-\left[e_{H}\left(r_{1}\right)+e_{H}\left(r_{2}\right)\right], \\
\delta \bar{w}_{L}-\left[e_{L}\left(r_{1}\right)+e_{L}\left(r_{2}\right)\right] & >\delta \bar{w}_{H}-\left[e_{L}\left(r_{1}^{\prime}\right)+e_{L}\left(r_{2}^{\prime}\right)\right],
\end{aligned}
$$

which is a contradiction with the premise that $\left(r_{1}, r_{2}\right)$ is a solution to (11).

Hence, the set of separating equilibria satisfying the intuitive criterion and the set of solutions to (11) coincide. Now, we show that (11) can be replaced by (2). Note that $\left(r_{1}^{*}, r_{2}^{*}\right) \in B$ and

$$
\delta \bar{w}_{H}-\left[e_{H}\left(r_{1}^{*}\right)+e_{H}\left(r_{2}^{*}\right)\right] \geq \delta \bar{w}_{H}-\left[e_{H}\left(r_{1}^{\prime}\right)+e_{H}\left(r_{2}^{\prime}\right)\right] \text { for any }\left(r_{1}^{\prime}, r_{2}^{\prime}\right) \in B .
$$

Since the set of $\left(r_{1}, r_{2}\right)$ satisfying ICs in (1) is a subset of $B$,

$$
\delta \bar{w}_{H}-\left[e_{H}\left(r_{1}^{*}\right)+e_{H}\left(r_{2}^{*}\right)\right] \geq \delta \bar{w}_{H}-\left[e_{H}\left(r_{1}^{\prime}\right)+e_{H}\left(r_{2}^{\prime}\right)\right] \text { for any }\left(r_{1}^{\prime}, r_{2}^{\prime}\right) \text { satisfying (1). }
$$

It follows from the IC for the high type that

$$
\delta \bar{w}_{H}-\left[e_{H}\left(r_{1}^{*}\right)+e_{H}\left(r_{2}^{*}\right)\right] \geq \delta \bar{w}_{H}-\left[e_{H}\left(r_{1}^{\prime}\right)+e_{H}\left(r_{2}^{\prime}\right)\right] \geq \delta \bar{w}_{L}-\left[e_{H}\left(r_{L}\right)+e_{H}\left(r_{L}\right)\right],
$$

which in turn implies that $\left(r_{1}^{*}, r_{2}^{*}\right)$ satisfies (1). Hence, (11) can be replaced by (2).

Proof of Proposition 1. (i) If $\left(r_{H}, r_{H}\right) \in B,\left(r_{1}^{*}, r_{2}^{*}\right)=\left(r_{H}, r_{H}\right)$. Let $\left(r_{H}, r_{H}\right) \notin B$. Denote

$$
\bar{B}:=\left\{\left(r_{1}, r_{2}\right) \in \mathbb{R}_{+}^{2} \mid \delta \bar{w}_{L}-\left[e_{L}\left(r_{L}\right)+e_{L}\left(r_{L}\right)\right]=\delta \bar{w}_{H}-\left[e_{L}\left(r_{1}\right)+e_{L}\left(r_{2}\right)\right]\right\} .
$$

Since $e_{q}$ is continuous, $\bar{B}$ is closed. In addition, $e_{L}$ is strictly convex and $\lim _{r \rightarrow+\infty} e_{q}(r)=$ $+\infty$, and for each $i=1,2$,

$e_{L}\left(r_{i}\right)=\delta \bar{w}_{H}-\delta \bar{w}_{L}+\left[e_{L}\left(r_{L}\right)+e_{L}\left(r_{L}\right)\right]-e_{L}\left(r_{j}\right) \leq \delta \bar{w}_{H}-\delta \bar{w}_{L}+\left[e_{L}\left(r_{L}\right)+e_{L}\left(r_{L}\right)\right]-e_{L}\left(r_{L}\right)$. 
Hence, $\bar{B}$ is bounded. It follows from the Weierstrass Theorem that $\delta \bar{w}_{H}-\left[e_{H}\left(r_{1}\right)+e_{H}\left(r_{2}\right)\right]$ attains a local maximum on $\bar{B}$ at $\left(r_{1}^{* *}, r_{2}^{* *}\right)$. Furthermore, for any $\left(r_{1}, r_{2}\right) \in B \backslash \bar{B}$,

$$
e_{L}\left(r_{1}\right)+e_{L}\left(r_{2}\right)>\delta \bar{w}_{H}-\delta \bar{w}_{L}+\left[e_{L}\left(r_{L}\right)+e_{L}\left(r_{L}\right)\right] .
$$

From $\left(r_{H}, r_{H}\right) \notin B$,

$$
e_{L}\left(r_{H}\right)+e_{L}\left(r_{H}\right)<\delta \bar{w}_{H}-\delta \bar{w}_{L}+\left[e_{L}\left(r_{L}\right)+e_{L}\left(r_{L}\right)\right] .
$$

By the Intermediate Value Theorem, there exists $\lambda \in(0,1)$ such that

$$
e_{L}\left(\lambda r_{1}+(1-\lambda) r_{H}\right)+e_{L}\left(\lambda r_{2}+(1-\lambda) r_{H}\right)=\delta \bar{w}_{H}-\delta \bar{w}_{L}+\left[e_{L}\left(r_{L}\right)+e_{L}\left(r_{L}\right)\right] .
$$

Since $e_{H}$ attains a unique global minimum at $r_{H}$,

$$
\delta \bar{w}_{H}-\left[e_{H}\left(\lambda r_{1}+(1-\lambda) r_{H}\right)+e_{H}\left(\lambda r_{2}+(1-\lambda) r_{H}\right)\right]>\delta \bar{w}_{H}-\left[e_{H}\left(r_{1}\right)+e_{H}\left(r_{2}\right)\right] .
$$

Thus, $\left(r_{1}^{* *}, r_{2}^{* *}\right)$ is also a global maximizer.

(ii) We divide this into two cases. Case 1 . At least one of $\left(r_{1}^{*}, r_{2}^{*}\right)$ is in $\left[r_{L}, r_{H}\right)$. WLOG, let $r_{1}^{*} \in\left[r_{L}, r_{H}\right)$. Since $e_{L}$ is strictly increasing on $\left[r_{L}, r_{H}\right)$, and $e_{H}$ is strictly decreasing on $\left[r_{L}, r_{H}\right)$, there is $r_{1}^{\prime}>r_{1}^{*}$ such that $\delta \bar{w}_{H}-\left[e_{H}\left(r_{1}^{\prime}\right)+e_{H}\left(r_{2}^{*}\right)\right]>\delta \bar{w}_{H}-\left[e_{H}\left(r_{1}^{*}\right)+e_{H}\left(r_{2}^{*}\right)\right]$ and $\left(r_{1}^{\prime}, r_{2}^{*}\right) \in B$, which leads to a contradiction.

Case 2. At least one of $\left(r_{1}^{*}, r_{2}^{*}\right)$ is in $\left[0, r_{L}\right)$. WLOG, let $r_{1}^{*} \in\left[0, r_{L}\right)$. Since $\lim _{r \rightarrow+\infty} e_{q}(r)=$ $+\infty$, and $e_{q}$ is continuous, given $r_{1}^{*} \in\left[0, r_{L}\right)$, there exists $r_{1}^{\prime}>r_{L}$ such that $e_{L}\left(r_{1}^{\prime}\right)=e_{L}\left(r_{1}^{*}\right)$. It follows from SMP that

$$
e_{L}\left(r_{1}^{\prime}\right)-e_{H}\left(r_{1}^{\prime}\right)>e_{L}\left(r_{1}^{*}\right)-e_{H}\left(r_{1}^{*}\right)
$$

which in turn entails $e_{H}\left(r_{1}^{\prime}\right)<e_{H}\left(r_{1}^{*}\right)$. Hence, $\delta \bar{w}_{H}-\left[e_{H}\left(r_{1}^{\prime}\right)+e_{H}\left(r_{2}^{*}\right)\right]>\delta \bar{w}_{H}-\left[e_{H}\left(r_{1}^{*}\right)+\right.$ $\left.e_{H}\left(r_{2}^{*}\right)\right]$ and $\left(r_{1}^{\prime}, r_{2}^{*}\right) \in B$. We have a contradiction.

Proof of Corollary 1. (i) By Proposition 1, the maximization problem (2) can be replaced by

$$
\max _{\left(r_{1}, r_{2}\right)} \delta \bar{w}_{H}-\left[e_{H}\left(r_{1}\right)+e_{H}\left(r_{2}\right)\right] \text { subject to }\left(r_{1}, r_{2}\right) \in \mathbb{R}_{++}^{2} \cap \bar{B} \text {. }
$$

Let

$$
L:=\delta \bar{w}_{H}-\left[e_{H}\left(r_{1}\right)+e_{H}\left(r_{2}\right)\right]+\lambda\left(\delta \bar{w}_{L}-\delta \bar{w}_{H}+\left[e_{L}\left(r_{1}\right)+e_{L}\left(r_{2}\right)\right]-\left[e_{L}\left(r_{L}\right)+e_{L}\left(r_{L}\right)\right]\right) .
$$


The constraint qualification condition is satisfied from the result of Proposition 1. Given the solution $\left(r_{1}^{*}, r_{2}^{*}\right)$ to $(13)$, it follows from the Theorem of Lagrange that there exists $\lambda^{*} \in \mathbb{R}$ such that

$$
\begin{aligned}
& -e_{H}^{\prime}\left(r_{1}^{*}\right)+\lambda^{*} e_{L}^{\prime}\left(r_{1}^{*}\right)=0, \\
& -e_{H}^{\prime}\left(r_{2}^{*}\right)+\lambda^{*} e_{L}^{\prime}\left(r_{2}^{*}\right)=0 .
\end{aligned}
$$

If one of $\left(r_{1}^{*}, r_{2}^{*}\right)$ is equal to $r_{H}$, then $\lambda^{*}=0$, so by (14), the other regulation rate must be $r_{H}$. We have a contradiction.

(ii) If $\left(r_{H}, r_{H}\right) \in B,\left(r_{1}^{*}, r_{2}^{*}\right)=\left(r_{H}, r_{H}\right)$, so it is trivially true. Let $\left(r_{H}, r_{H}\right) \notin B$. (14) entails that $\lambda^{*} \neq 0$ since otherwise $\left(r_{1}^{*}, r_{2}^{*}\right)=\left(r_{H}, r_{H}\right)$, a contradiction. Hence,

$$
\frac{e_{L}^{\prime}\left(r_{1}^{*}\right)}{e_{H}^{\prime}\left(r_{1}^{*}\right)}=\frac{e_{L}^{\prime}\left(r_{2}^{*}\right)}{e_{H}^{\prime}\left(r_{2}^{*}\right)}
$$

The result follows from the condition that $e_{L}^{\prime}(r) / e_{H}^{\prime}(r)$ is strictly monotone on $\left(r_{H},+\infty\right)$ and Proposition 1. The uniqueness is an easy consequence of the fact that $e_{H}$ is strictly increasing on $\left(r_{H},+\infty\right)$.

Proof of Proposition 2. (i) Denote $r_{Y}:=\arg \max _{r_{C} \in \mathbb{R}_{+}} f\left(r_{C}\right)-e_{H}\left(r_{C}\right)$, and a unique $r_{Y}$ is well defined from the properties of the functions $f$ and $e_{H}$. If $\left(r_{Y}, r_{H}\right) \in \mathbf{B}\left(w_{H}\right)$, $\left(r_{C}^{*}, r_{N}^{*}\right)=\left(r_{Y}, r_{H}\right)$. Let $\left(r_{Y}, r_{H}\right) \notin \mathbf{B}\left(w_{H}\right)$. Since $e_{q}$ is continuous, $\mathbf{B}\left(w_{H}\right)$ is closed. Define

$$
\begin{aligned}
& B_{H}\left(w_{H}\right):=\left\{\left(r_{C}, r_{N}\right) \in \mathbb{R}_{+}^{2} \mid \delta w_{H}-\left[e_{H}\left(r_{C}\right)+e_{H}\left(r_{N}\right)\right] \geq \delta \bar{w}_{L}-\left[e_{H}\left(r_{L}\right)+e_{H}\left(r_{L}\right)\right]\right\}, \\
& B_{L}\left(w_{H}\right):=\left\{\left(r_{C}, r_{N}\right) \in \mathbb{R}_{+}^{2} \mid \delta \bar{w}_{L}-\left[e_{L}\left(r_{L}\right)+e_{L}\left(r_{L}\right)\right] \geq \delta w_{H}-\left[e_{L}\left(r_{C}\right)+e_{L}\left(r_{N}\right)\right]\right\} .
\end{aligned}
$$

Then, $\mathbf{B}\left(w_{H}\right)=B_{H}\left(w_{H}\right) \cap B_{L}\left(w_{H}\right)$. Note that $e_{q}$ is strictly convex and $\lim _{r \rightarrow+\infty} e_{q}(r)=$ $+\infty$, and

$$
e_{H}\left(r_{C}\right)+e_{H}\left(r_{N}\right) \leq \delta w_{H}-\delta \bar{w}_{L}+\left[e_{H}\left(r_{L}\right)+e_{H}\left(r_{L}\right)\right] .
$$

Hence, $B_{H}\left(w_{H}\right)$ is bounded. Since $\mathbf{B}\left(w_{H}\right) \subseteq B_{H}\left(w_{H}\right), \mathbf{B}\left(w_{H}\right)$ is a compact set. It follows from the Weierstrass Theorem that $f\left(r_{C}\right)-\left[e_{H}\left(r_{C}\right)+e_{H}\left(r_{N}\right)\right]$ attains a global maximum on $\mathbf{B}\left(w_{H}\right)$ at $\left(r_{C}^{*}, r_{N}^{*}\right)$.

(ii) If $\left(r_{Y}, r_{H}\right) \in B\left(w_{H}\right),\left(r_{C}^{*}, r_{N}^{*}\right)=\left(r_{Y}, r_{H}\right)$, and since $f^{\prime}\left(r_{H}\right)-e_{H}^{\prime}\left(r_{H}\right)<0$ and for all $r \geq 0, f^{\prime \prime}(r)-e_{H}^{\prime \prime}(r)<0$, we have $r_{Y}<r_{H}$. Let $\left(r_{Y}, r_{H}\right) \notin \mathbf{B}\left(w_{H}\right)$.

Part 1. $r_{N}^{*} \geq r_{H}$. Case 1. $r_{N}^{*} \in\left[r_{L}, r_{H}\right)$. Since $e_{L}$ is strictly increasing on $\left[r_{L}, r_{H}\right)$, and $e_{H}$ is strictly decreasing on $\left[r_{L}, r_{H}\right)$, there is $r_{N}^{\prime}>r_{N}^{*}$ such that $f\left(r_{C}^{*}\right)-\left[e_{H}\left(r_{C}^{*}\right)+e_{H}\left(r_{N}^{\prime}\right)\right]$ $>f\left(r_{C}^{*}\right)-\left[e_{H}\left(r_{C}^{*}\right)+e_{H}\left(r_{N}^{*}\right)\right]$ and $\left(r_{C}^{*}, r_{N}^{\prime}\right) \in \mathbf{B}\left(w_{H}\right)$, which leads to a contradiction. 
Case 2. $r_{N}^{*} \in\left[0, r_{L}\right)$. Since $\lim _{r \rightarrow+\infty} e_{q}(r)=+\infty$, and $e_{q}$ is continuous, given $r_{N}^{*} \in$ $\left[0, r_{L}\right)$, there exists $r_{N}^{\prime}>r_{L}$ such that $e_{L}\left(r_{N}^{\prime}\right)=e_{L}\left(r_{N}^{*}\right)$. It follows from SMP that

$$
e_{L}\left(r_{N}^{\prime}\right)-e_{H}\left(r_{N}^{\prime}\right)>e_{L}\left(r_{N}^{*}\right)-e_{H}\left(r_{N}^{*}\right) \text {, }
$$

which in turn entails $e_{H}\left(r_{N}^{\prime}\right)<e_{H}\left(r_{N}^{*}\right)$. Hence, $f\left(r_{C}^{*}\right)-\left[e_{H}\left(r_{C}^{*}\right)+e_{H}\left(r_{N}^{\prime}\right)\right]>f\left(r_{C}^{*}\right)-$ $\left[e_{H}\left(r_{C}^{*}\right)+e_{H}\left(r_{N}^{*}\right)\right]$ and $\left(r_{C}^{*}, r_{N}^{\prime}\right) \in \mathbf{B}\left(w_{H}\right)$. We have a contradiction.

Part 2. $r_{N}^{*}>r_{C}^{*}>0$. First, we show $r_{C}^{*}>0$. It follows from the result in Part 1. above that the constraint qualification condition is satisfied. Let

$$
\begin{aligned}
\mathcal{L}:= & f\left(r_{C}\right)-\left[e_{H}\left(r_{C}\right)+e_{H}\left(r_{N}\right)\right]+\mu\left(\delta w_{H}-\delta \bar{w}_{L}-\left[e_{H}\left(r_{C}\right)+e_{H}\left(r_{N}\right)\right]+\left[e_{H}\left(r_{L}\right)+e_{H}\left(r_{L}\right)\right]\right) \\
& +\lambda\left(\delta \bar{w}_{L}-\delta w_{H}+\left[e_{L}\left(r_{C}\right)+e_{L}\left(r_{N}\right)\right]-\left[e_{L}\left(r_{L}\right)+e_{L}\left(r_{L}\right)\right]\right)+\eta r_{C} .
\end{aligned}
$$

The Theorem of Kuhn and Tucker entails that there exists $\left(\mu^{*}, \lambda^{*}, \eta^{*}\right) \in \mathbb{R}_{+}^{3}$ such that

$$
\begin{aligned}
f^{\prime}\left(r_{C}^{*}\right)-e_{H}^{\prime}\left(r_{C}^{*}\right)-\mu^{*} e_{H}^{\prime}\left(r_{C}^{*}\right)+\lambda^{*} e_{L}^{\prime}\left(r_{C}^{*}\right)+\eta^{*} & =0, \\
-e_{H}^{\prime}\left(r_{N}^{*}\right)-\mu^{*} e_{H}^{\prime}\left(r_{N}^{*}\right)+\lambda^{*} e_{L}^{\prime}\left(r_{N}^{*}\right) & =0 .
\end{aligned}
$$

Suppose $r_{C}^{*}=0$. Since $r_{N}^{*} \geq r_{H}$, we have $e_{L}^{\prime}\left(r_{N}^{*}\right)>e_{H}^{\prime}\left(r_{N}^{*}\right)>0$, which implies $1+\mu^{*}>\lambda^{*}$. Now, It follows from $e_{H}^{\prime}(0)=e_{L}^{\prime}(0)<0$ and $f^{\prime}(0)=0$ that

$$
0=f^{\prime}(0)-e_{H}^{\prime}(0)-\mu^{*} e_{H}^{\prime}(0)+\lambda^{*} e_{L}^{\prime}(0)+\eta^{*}>\eta^{*} \geq 0,
$$

which is a contradiction. Since $r_{C}^{*}>0$ and $r_{N}^{*}>0,(6)$ can be rewritten as

$$
\max _{\left(r_{C}, r_{N}\right)} f\left(r_{C}\right)-\left[e_{H}\left(r_{C}\right)+e_{H}\left(r_{N}\right)\right] \text { subject to }\left(r_{C}, r_{N}\right) \in \mathbb{R}_{++}^{2} \cap \mathbf{B}\left(w_{H}\right) .
$$

Let

$$
\begin{aligned}
\mathcal{L}:= & f\left(r_{C}\right)-\left[e_{H}\left(r_{C}\right)+e_{H}\left(r_{N}\right)\right]+\mu\left(\delta w_{H}-\delta \bar{w}_{L}-\left[e_{H}\left(r_{C}\right)+e_{H}\left(r_{N}\right)\right]+\left[e_{H}\left(r_{L}\right)+e_{H}\left(r_{L}\right)\right]\right) \\
& +\lambda\left(\delta \bar{w}_{L}-\delta w_{H}+\left[e_{L}\left(r_{C}\right)+e_{L}\left(r_{N}\right)\right]-\left[e_{L}\left(r_{L}\right)+e_{L}\left(r_{L}\right)\right]\right) .
\end{aligned}
$$

The Theorem of Kuhn and Tucker entails that there exists $\left(\mu^{*}, \lambda^{*}\right) \in \mathbb{R}_{+}^{2}$ such that

$$
\begin{aligned}
f^{\prime}\left(r_{C}^{*}\right)-e_{H}^{\prime}\left(r_{C}^{*}\right)-\mu^{*} e_{H}^{\prime}\left(r_{C}^{*}\right)+\lambda^{*} e_{L}^{\prime}\left(r_{C}^{*}\right) & =0, \\
-e_{H}^{\prime}\left(r_{N}^{*}\right)-\mu^{*} e_{H}^{\prime}\left(r_{N}^{*}\right)+\lambda^{*} e_{L}^{\prime}\left(r_{N}^{*}\right) & =0 .
\end{aligned}
$$

Suppose $r_{C}^{*}=r_{N}^{*}$. Then, we have $f^{\prime}\left(r_{C}^{*}\right)=0$, a contradiction. Thus, $r_{C}^{*} \neq r_{N}^{*}$. Suppose $r_{C}^{*}>r_{N}^{*}$. Let $r_{C}^{\prime}=r_{N}^{*}$ and $r_{N}^{\prime}=r_{C}^{*}$. Since $f$ is strictly decreasing,

$f\left(r_{C}^{\prime}\right)-\left\{e_{H}\left(r_{C}^{\prime}\right)+e_{H}\left(r_{N}^{\prime}\right)\right\}=f\left(r_{N}^{*}\right)-\left\{e_{H}\left(r_{N}^{*}\right)+e_{H}\left(r_{C}^{*}\right)\right\}>f\left(r_{C}^{*}\right)-\left\{e_{H}\left(r_{C}^{*}\right)+e_{H}\left(r_{N}^{*}\right)\right\}$. 
Moreover, both ICs are satisfied. Therefore, we have a contradiction.

Proof of Proposition 3. We rewrite the incentive compatibility conditions in $\mathbf{B}\left(w_{H}\right)$ :

$$
\begin{aligned}
\delta w_{H}-\left[e_{H}\left(r_{C}\right)+e_{H}\left(r_{N}\right)\right] & \geq \delta \bar{w}_{L}-\left[e_{H}\left(r_{L}\right)+e_{H}\left(r_{L}\right)\right]\left(\mathrm{IC}_{H}\right), \\
\delta \bar{w}_{L}-\left[e_{L}\left(r_{L}\right)+e_{L}\left(r_{L}\right)\right] & \geq \delta w_{H}-\left[e_{L}\left(r_{C}\right)+e_{L}\left(r_{N}\right)\right]\left(\mathrm{IC}_{L}\right) .
\end{aligned}
$$

Note that the individual rationality condition of the high type results from (12). The value function $V$ and the set-valued function $R^{*}:=\left(R_{C}^{*}, R_{N}^{*}\right)$ are given by

$$
\begin{aligned}
& V\left(w_{H}\right)=\max _{\left(r_{C}, r_{N}\right)} f\left(r_{C}\right)-\left[e_{H}\left(r_{C}\right)+e_{H}\left(r_{N}\right)\right] \text { subject to }\left(r_{C}, r_{N}\right) \in \mathbf{B}\left(w_{H}\right), \\
& R^{*}\left(w_{H}\right)=\arg \max _{\left(r_{C}, r_{N}\right)} f\left(r_{C}\right)-\left[e_{H}\left(r_{C}\right)+e_{H}\left(r_{N}\right)\right] \text { subject to }\left(r_{C}, r_{N}\right) \in \mathbf{B}\left(w_{H}\right) .
\end{aligned}
$$

Let $r^{*}\left(w_{H}\right) \in R^{*}\left(w_{H}\right)$. Note that for any pair $w_{H}^{\prime}>w_{H}, B_{H}\left(w_{H}\right) \subset B_{H}\left(w_{H}^{\prime}\right)$, and it follows from $\lim _{r \rightarrow+\infty} e_{q}(r)=+\infty$ that there exists $\widehat{w}_{H}$ such that for any $w_{H}>\widehat{w}_{H}$,

$$
\text { if }\left(r_{C}, r_{N}\right) \in B_{H}\left(w_{H}\right) \backslash B_{H}\left(\widehat{w}_{H}\right) \text {, then } f\left(r_{C}\right)-\left[e_{H}\left(r_{C}\right)+e_{H}\left(r_{N}\right)\right]<0 \text {. }
$$

Define

$$
\widehat{\mathbf{B}}\left(w_{H}\right):=\left\{\left(r_{C}, r_{N}\right) \in B_{H}\left(\widehat{w}_{H}\right) \mid \begin{array}{c}
\delta w_{H}-\left[e_{H}\left(r_{C}\right)+e_{H}\left(r_{N}\right)\right] \geq \delta \bar{w}_{L}-\left[e_{H}\left(r_{L}\right)+e_{H}\left(r_{L}\right)\right] \\
\delta \bar{w}_{L}-\left[e_{L}\left(r_{L}\right)+e_{L}\left(r_{L}\right)\right] \geq \delta w_{H}-\left[e_{L}\left(r_{C}\right)+e_{L}\left(r_{N}\right)\right]
\end{array}\right\} .
$$

Thus, (6) can be replaced by

$$
\max _{\left(r_{C}, r_{N}\right)} f\left(r_{C}\right)-\left[e_{H}\left(r_{C}\right)+e_{H}\left(r_{N}\right)\right] \text { subject to }\left(r_{C}, r_{N}\right) \in \widehat{\mathbf{B}}\left(w_{H}\right) \text {. }
$$

Step 1. $\widehat{\mathbf{B}}: \Pi \rightarrow B_{H}\left(\widehat{w}_{H}\right)$ is a continuous correspondence.

Let a sequence $w_{H}^{m} \in \Pi$ converge to some $w_{H} \in \Pi$, and a sequence $\left(r_{C}^{m}, r_{N}^{m}\right) \in \widehat{\mathbf{B}}\left(w_{H}^{m}\right)$ converge to $\left(r_{C}, r_{N}\right)$, then

$$
\begin{aligned}
\delta w_{H}^{m}-\left[e_{H}\left(r_{C}^{m}\right)+e_{H}\left(r_{N}^{m}\right)\right] & \geq \delta \bar{w}_{L}-\left[e_{H}\left(r_{L}\right)+e_{H}\left(r_{L}\right)\right] \\
\delta \bar{w}_{L}-\left[e_{L}\left(r_{L}\right)+e_{L}\left(r_{L}\right)\right] & \geq \delta w_{H}^{m}-\left[e_{L}\left(r_{C}^{m}\right)+e_{L}\left(r_{N}^{m}\right)\right]
\end{aligned}
$$

implies, in the limit, that

$$
\begin{aligned}
\delta w_{H}-\left[e_{H}\left(r_{C}\right)+e_{H}\left(r_{N}\right)\right] & \geq \delta \bar{w}_{L}-\left[e_{H}\left(r_{L}\right)+e_{H}\left(r_{L}\right)\right] \\
\delta \bar{w}_{L}-\left[e_{L}\left(r_{L}\right)+e_{L}\left(r_{L}\right)\right] & \geq \delta w_{H}-\left[e_{L}\left(r_{C}\right)+e_{L}\left(r_{N}\right)\right] .
\end{aligned}
$$


Hence, $\left(r_{C}, r_{N}\right) \in \widehat{\mathbf{B}}\left(w_{H}\right)$. Since the image set of $\widehat{\mathbf{B}}, B_{H}\left(\widehat{w}_{H}\right)$, is compact, this establishes the upper semicontinuity of the correspondence $\widehat{\mathbf{B}}$. Define $\stackrel{o}{\widehat{\mathbf{B}}}\left(w_{H}\right):=\left\{\left(r_{C}, r_{N}\right) \in B_{H}\left(\widehat{w}_{H}\right) \mid \begin{array}{c}\delta w_{H}-\left[e_{H}\left(r_{C}\right)+e_{H}\left(r_{N}\right)\right]>\delta \bar{w}_{L}-\left[e_{H}\left(r_{L}\right)+e_{H}\left(r_{L}\right)\right] \\ \delta \bar{w}_{L}-\left[e_{L}\left(r_{L}\right)+e_{L}\left(r_{L}\right)\right]>\delta w_{H}-\left[e_{L}\left(r_{C}\right)+e_{L}\left(r_{N}\right)\right]\end{array}\right\}$

Now, let a sequence $w_{H}^{m} \in \Pi$ converge to $w_{H} \in \Pi$ and suppose that $\left(r_{C}, r_{N}\right) \in \widehat{O} \widehat{\mathbf{B}}\left(w_{H}\right)$. Divide $e_{L}$ into two functions such that $e_{L l}:\left[0, r_{L}\right) \rightarrow \mathbb{R}_{+}$with $e_{L l}=e_{L}$ and $e_{L r}:\left[r_{L},+\infty\right) \rightarrow$ $\mathbb{R}_{+}$with $e_{L r}=e_{L}$. Define $\left(r_{C}^{m}, r_{N}^{m}\right)$ as

$r_{C}^{m}=\left\{\begin{array}{cc}e_{L l}^{-1}\left(e_{L}\left(r_{C}\right)+\frac{\delta w_{H}^{m}-\delta w_{H}}{2}\right) & \text { if } r_{C} \in\left[0, r_{L}\right) \\ e_{L r}^{-1}\left(e_{L}\left(r_{C}\right)+\frac{\delta w_{H}^{m}-\delta w_{H}}{2}\right) & \text { if } r_{C} \in\left[r_{L},+\infty\right)\end{array}, r_{N}^{m}=\left\{\begin{array}{cc}e_{L l}^{-1}\left(e_{L}\left(r_{N}\right)+\frac{\delta w_{H}^{m}-\delta w_{H}}{2}\right) & \text { if } r_{N} \in\left[0, r_{L}\right) \\ e_{L r}^{-1}\left(e_{L}\left(r_{N}\right)+\frac{\delta w_{H}^{m}-\delta w_{H}}{2}\right) & \text { if } r_{N} \in\left[r_{L},+\infty\right)\end{array}\right.\right.$.

Then, $\left(r_{C}^{m}, r_{N}^{m}\right) \rightarrow\left(r_{C}, r_{N}\right)$. From the construction, the second inequality in (22) is satisfied.

Moreover, there exists $M \in \mathbb{N}$ such that for all $m \geq M, \delta w_{H}^{m}-\left[e_{H}\left(r_{C}^{m}\right)+e_{H}\left(r_{N}^{m}\right)\right]>\delta \bar{w}_{L}-$ $\left[e_{H}\left(r_{L}\right)+e_{H}\left(r_{L}\right)\right]$. Hence, for $m \geq M,\left(r_{C}^{m}, r_{N}^{m}\right) \in \stackrel{o}{\widehat{\mathbf{B}}}\left(w_{H}^{m}\right)$. Thus, $\stackrel{o}{\widehat{B}}$ is lower semicontinuous. However, we have closure $\left(\widehat{\mathbf{B}}\left(w_{H}\right)\right)=\widehat{\mathbf{B}}\left(w_{H}\right)$. Since the closure of a lower semicontinuous correspondence is lower semicontinuous, this establishes the lower semicontinuity of the correspondence $\widehat{\mathbf{B}}$.

Step 2. The existence of $w_{H}^{*}$.

It follows from the Maximum Theorem that $R^{*}$ is upper semicontinuous. Then, there exists $w_{H}^{*} \in\left[\bar{w}_{L}, \widehat{w}_{H}\right]$ such that

$$
w_{H}^{*}:=\arg \max _{w_{H} \in\left[\bar{w}_{L}, \widehat{w}_{H}\right]} V\left(w_{H}\right) .
$$

Step 3. The existence of a collusion-maximizing profile $\left(\mathbf{r}^{*}\left(w_{H}^{*}\right), w_{H}^{*}\right)$ satisfies (a) and (b).

Case 1. $\left(r_{H}, r_{H}\right) \in B$. Then, $\left(r_{1}^{*}, r_{2}^{*}\right)=\left(r_{H}, r_{H}\right)$, and

$$
\delta \bar{w}_{L}-\left[e_{L}\left(r_{L}\right)+e_{L}\left(r_{L}\right)\right] \geq \delta \bar{w}_{H}-\left[e_{L}\left(r_{H}\right)+e_{L}\left(r_{H}\right)\right] .
$$

It follows from Proposition 2 that there exists $r_{C}^{*}<r_{N}^{*}$ such that $\left(r_{C}^{*}, r_{N}^{*}\right) \in \widehat{\mathbf{B}}\left(\bar{w}_{H}\right)$ and

$$
f\left(r_{C}^{*}\right)-\left[e_{H}\left(r_{C}^{*}\right)+e_{H}\left(r_{N}^{*}\right)\right]>f\left(r_{H}\right)-\left[e_{H}\left(r_{H}\right)+e_{H}\left(r_{H}\right)\right] .
$$

By the definition of $w_{H}^{*}$,

$u_{C}\left(w_{H}^{*}, r_{C}^{*}\left(w_{H}^{*}\right)\right)+u_{H}\left(r_{C}^{*}\left(w_{H}^{*}\right), r_{N}^{*}\left(w_{H}^{*}\right), w_{H}^{*}\right) \geq u_{C}\left(\bar{w}_{H}, r_{C}^{*}\left(\bar{w}_{H}\right)\right)+u_{H}\left(r_{C}^{*}\left(\bar{w}_{H}\right), r_{N}^{*}\left(\bar{w}_{H}\right), \bar{w}_{H}\right)$. 
(24) implies the strict inequality below.

$$
\begin{aligned}
& u_{C}\left(\bar{w}_{H}, r_{C}^{*}\left(\bar{w}_{H}\right)\right)+u_{H}\left(r_{C}^{*}\left(\bar{w}_{H}\right), r_{N}^{*}\left(\bar{w}_{H}\right), \bar{w}_{H}\right)>u_{C}\left(\bar{w}_{H}, r_{H}\right)+u_{H}\left(r_{H}, r_{H}, \bar{w}_{H}\right) \\
= & \theta\left[\theta y_{H}\left(r_{H}\right)+(1-\theta) y_{L}\left(r_{H}\right)\right]+(1-\theta)\left[\theta y_{H}\left(r_{L}\right)+(1-\theta) y_{L}\left(r_{L}\right)-\bar{w}_{L}\right]+(\delta-1) \theta \bar{w}_{H}-\theta\left[e_{H}\left(r_{H}\right)+e_{H}\left(r_{H}\right)\right] \\
= & \theta\left[\theta y_{H}\left(r_{H}\right)+(1-\theta) y_{H}\left(r_{L}\right)\right]+(1-\theta)\left[\theta y_{L}\left(r_{H}\right)+(1-\theta) y_{L}\left(r_{L}\right)-\bar{w}_{L}\right]+(\delta-1) \theta \bar{w}_{H}-\theta\left[e_{H}\left(r_{1}^{*}\right)+e_{H}\left(r_{2}^{*}\right)\right] \\
= & \theta\left\{\delta \bar{w}_{H}-\left[e_{H}\left(r_{1}^{*}\right)+e_{H}\left(r_{2}^{*}\right)\right]\right\}+\theta(1-\delta) \bar{w}_{H}+(\delta-1) \theta \bar{w}_{H} .
\end{aligned}
$$

The last equality follows from $\theta y_{H}\left(r_{H}\right)+(1-\theta) y_{H}\left(r_{L}\right)-\bar{w}_{H}=0$ and $\theta y_{L}\left(r_{H}\right)+(1-$ $\theta) y_{L}\left(r_{L}\right)-\bar{w}_{L}=0$, and the last equation is equal to $u_{H}\left(r_{1}^{*}, r_{2}^{*}, \bar{w}_{H}\right)$.

Case 2. $\left(r_{H}, r_{H}\right) \notin B$. It follows from Corollary 1 that $r_{1}^{*}>r_{H}$ and $r_{2}^{*}>r_{H}$. Since $r_{H}>r_{L}$ and $r_{2}^{*}>r_{L}$, SMP entails that

$$
e_{L}\left(r_{H}\right)-e_{H}\left(r_{H}\right)+e_{L}\left(r_{2}^{*}\right)-e_{H}\left(r_{2}^{*}\right)>e_{L}\left(r_{L}\right)-e_{H}\left(r_{L}\right)+e_{L}\left(r_{L}\right)-e_{H}\left(r_{L}\right) .
$$

Then,

$\left[e_{L}\left(r_{H}\right)+e_{L}\left(r_{2}^{*}\right)\right]-\left[e_{L}\left(r_{L}\right)+e_{L}\left(r_{L}\right)\right]+\delta \bar{w}_{L}>\left[e_{H}\left(r_{H}\right)+e_{H}\left(r_{2}^{*}\right)\right]-\left[e_{H}\left(r_{L}\right)+e_{H}\left(r_{L}\right)\right]+\delta \bar{w}_{L}$.

In addition, since $r_{1}^{*}>r_{H}$ and $e_{H}$ is strictly increasing on $\left[r_{H},+\infty\right)$,

$\delta \bar{w}_{H} \geq\left[e_{H}\left(r_{1}^{*}\right)+e_{H}\left(r_{2}^{*}\right)\right]-\left[e_{H}\left(r_{L}\right)+e_{H}\left(r_{L}\right)\right]+\delta \bar{w}_{L}>\left[e_{H}\left(r_{H}\right)+e_{H}\left(r_{2}^{*}\right)\right]-\left[e_{H}\left(r_{L}\right)+e_{H}\left(r_{L}\right)\right]+\delta \bar{w}_{L}$.

Choose $w_{H}^{\prime}$ such that

$$
\begin{aligned}
& \min \left\{\left[e_{L}\left(r_{H}\right)+e_{L}\left(r_{2}^{*}\right)\right]-\left[e_{L}\left(r_{L}\right)+e_{L}\left(r_{L}\right)\right]+\delta \bar{w}_{L}, \delta \bar{w}_{H}\right\}>\delta w_{H}^{\prime}, \\
& \delta w_{H}^{\prime}>\left[e_{H}\left(r_{H}\right)+e_{H}\left(r_{2}^{*}\right)\right]-\left[e_{H}\left(r_{L}\right)+e_{H}\left(r_{L}\right)\right]+\delta \bar{w}_{L} .
\end{aligned}
$$

By the definition of $w_{H}^{*}$,

$u_{C}\left(w_{H}^{*}, r_{C}^{*}\left(w_{H}^{*}\right)\right)+u_{H}\left(r_{C}^{*}\left(w_{H}^{*}\right), r_{N}^{*}\left(w_{H}^{*}\right), w_{H}^{*}\right) \geq u_{C}\left(w_{H}^{\prime}, r_{C}^{*}\left(w_{H}^{\prime}\right)\right)+u_{H}\left(r_{C}^{*}\left(w_{H}^{\prime}\right), r_{N}^{*}\left(w_{H}^{\prime}\right), w_{H}^{\prime}\right)$.

From the construction, we have $\left(r_{H}, r_{2}^{*}\right) \in \widehat{\mathbf{B}}\left(w_{H}^{\prime}\right)$. Hence,

$$
u_{C}\left(w_{H}^{\prime}, r_{C}^{*}\left(w_{H}^{\prime}\right)\right)+u_{H}\left(r_{C}^{*}\left(w_{H}^{\prime}\right), r_{N}^{*}\left(w_{H}^{\prime}\right), w_{H}^{\prime}\right) \geq u_{C}\left(w_{H}^{\prime}, r_{H}\right)+u_{H}\left(r_{H}, r_{2}^{*}, w_{H}^{\prime}\right) .
$$

Since $r_{1}^{*}>r_{H}$ and $e_{H}$ is strictly increasing on $\left[r_{H},+\infty\right)$,

$$
\begin{aligned}
& u_{C}\left(w_{H}^{\prime}, r_{H}\right)+u_{H}\left(r_{H}, r_{2}^{*}, w_{H}^{\prime}\right)=\theta\left[\theta y_{H}\left(r_{H}\right)+(1-\theta) y_{L}\left(r_{H}\right)\right]+(1-\theta)\left[\theta y_{H}\left(r_{L}\right)+(1-\theta) y_{L}\left(r_{L}\right)-\bar{w}_{L}\right] \\
& +(\delta-1) \theta w_{H}^{\prime}-\theta\left[e_{H}\left(r_{H}\right)+e_{H}\left(r_{2}^{*}\right)\right] \\
> & \theta\left[\theta y_{H}\left(r_{H}\right)+(1-\theta) y_{L}\left(r_{H}\right)\right]+(1-\theta)\left[\theta y_{H}\left(r_{L}\right)+(1-\theta) y_{L}\left(r_{L}\right)-\bar{w}_{L}\right]+(\delta-1) \theta w_{H}^{\prime}-\theta\left[e_{H}\left(r_{1}^{*}\right)+e_{H}\left(r_{2}^{*}\right)\right] \\
= & \theta\left[\theta y_{H}\left(r_{H}\right)+(1-\theta) y_{H}\left(r_{L}\right)\right]+(1-\theta)\left[\theta y_{L}\left(r_{H}\right)+(1-\theta) y_{L}\left(r_{L}\right)-\bar{w}_{L}\right]+(\delta-1) \theta w_{H}^{\prime}-\theta\left[e_{H}\left(r_{1}^{*}\right)+e_{H}\left(r_{2}^{*}\right)\right] \\
= & \theta\left\{\delta \bar{w}_{H}-\left[e_{H}\left(r_{1}^{*}\right)+e_{H}\left(r_{2}^{*}\right)\right]\right\}+\theta(1-\delta)\left(\bar{w}_{H}-w_{H}^{\prime}\right)>u_{H}\left(r_{1}^{*}, r_{2}^{*}, \bar{w}_{H}\right) .
\end{aligned}
$$


The last equality follows from $\theta y_{H}\left(r_{H}\right)+(1-\theta) y_{H}\left(r_{L}\right)-\bar{w}_{H}=0$ and $\theta y_{L}\left(r_{H}\right)+(1-$ $\theta) y_{L}\left(r_{L}\right)-\bar{w}_{L}=0$. Thus, (a) in (5) is satisfied, and (b) results from Proposition 2.

Proof of Proposition 4. First, we show that both ICs must be binding. We divide the proof into three cases.

Case 1. Suppose that both ICs in (19) given $\mathbf{B}\left(w_{H}^{*}\right)$ are not binding, Then, from (18), $\left(r_{C}^{*}, r_{N}^{*}\right)=\left(r_{Y}, r_{H}\right)$ and

$$
A:=\left[\begin{array}{cc}
f^{\prime \prime}\left(r_{C}^{*}\right)-e_{H}^{\prime \prime}\left(r_{C}^{*}\right) & 0 \\
0 & -e_{H}^{\prime \prime}\left(r_{N}^{*}\right)
\end{array}\right] .
$$

Since $f^{\prime \prime}\left(r_{C}^{*}\right)-e_{H}^{\prime \prime}\left(r_{C}^{*}\right)<0$ and $-e_{H}^{\prime \prime}\left(r_{N}^{*}\right)<0, A$ is negative definite. It follows from the Implicit Function Theorem that $r^{*}$ is a unique function of $w_{H}$ and differentiable. The Envelope Theorem entails that

$$
\frac{\partial V\left(w_{H}^{*}\right)}{\partial w_{H}}=(\delta-1) \theta<0,
$$

which in turn implies a corner solution at $w_{H}^{*}=\bar{w}_{L}$. However, if $w_{H}^{*}=\bar{w}_{L},\left(r_{C}^{*}, r_{N}^{*}\right)=$ $\left(r_{L}, r_{L}\right)$, a contradiction.

Case 2. Suppose that given $\mathbf{B}\left(w_{H}^{*}\right), \mathrm{IC}_{H}$ is binding, but $\mathrm{IC}_{L}$ is not binding. Then, from (18), $r_{N}^{*}=r_{H}$ and $\mu^{*}>0$ (If $\mu^{*}=0,\left(r_{C}^{*}, r_{N}^{*}\right)=\left(r_{Y}, r_{H}\right)$ ). By (18) and $\mathrm{IC}_{H}$,

$$
A_{H}:=\left[\begin{array}{ccc}
f^{\prime \prime}\left(r_{C}^{*}\right)-e_{H}^{\prime \prime}\left(r_{C}^{*}\right)-\mu^{*} e_{L}^{\prime \prime}\left(r_{C}^{*}\right) & 0 & e_{H}^{\prime}\left(r_{C}^{*}\right) \\
0 & -e_{H}^{\prime \prime}\left(r_{N}^{*}\right)-\mu^{*} e_{L}^{\prime \prime}\left(r_{N}^{*}\right) & e_{H}^{\prime}\left(r_{N}^{*}\right) \\
e_{H}^{\prime}\left(r_{C}^{*}\right) & e_{H}^{\prime}\left(r_{N}^{*}\right) & 0
\end{array}\right] .
$$

Since $-f^{\prime \prime}\left(r_{C}^{*}\right)+e_{H}^{\prime \prime}\left(r_{C}^{*}\right)>0$ and $e_{H}^{\prime \prime}\left(r_{N}^{*}\right)>0$,

$\operatorname{det} A_{H}=\left[e_{H}^{\prime}\left(r_{N}^{*}\right)\right]^{2}\left[-f^{\prime \prime}\left(r_{C}^{*}\right)+e_{H}^{\prime \prime}\left(r_{C}^{*}\right)+\mu^{*} e_{L}^{\prime \prime}\left(r_{C}^{*}\right)\right]+\left[e_{H}^{\prime}\left(r_{C}^{*}\right)\right]^{2}\left[e_{H}^{\prime \prime}\left(r_{N}^{*}\right)+\mu^{*} e_{L}^{\prime \prime}\left(r_{N}^{*}\right)\right]>0$.

It follows from the Implicit Function Theorem that $r^{*}$ is a unique function of $w_{H}$ and differentiable. The Envelope Theorem entails that

$$
\frac{\partial V\left(w_{H}^{*}\right)}{\partial w_{H}}=\mu^{*}>0
$$

and we have a corner solution at $w_{H}^{*}=\widehat{w}_{H}$, which contradicts (20).

Case 3. Suppose that given $\mathbf{B}\left(w_{H}^{*}\right), \mathrm{IC}_{L}$ is binding and $\mathrm{IC}_{H}$ is not binding. Then, from (18), $r_{N}^{*}=r_{H}$ and $\lambda^{*}>0$ (If $\lambda^{*}=0,\left(r_{C}^{*}, r_{N}^{*}\right)=\left(r_{Y}, r_{H}\right)$ ). By (18) and $\mathrm{IC}_{L}$,

$$
A_{L}:=\left[\begin{array}{ccc}
f^{\prime \prime}\left(r_{C}^{*}\right)-e_{H}^{\prime \prime}\left(r_{C}^{*}\right)+\lambda^{*} e_{L}^{\prime \prime}\left(r_{C}^{*}\right) & 0 & e_{L}^{\prime}\left(r_{C}^{*}\right) \\
0 & -e_{H}^{\prime \prime}\left(r_{N}^{*}\right)+\lambda^{*} e_{L}^{\prime \prime}\left(r_{N}^{*}\right) & e_{L}^{\prime}\left(r_{N}^{*}\right) \\
e_{L}^{\prime}\left(r_{C}^{*}\right) & e_{L}^{\prime}\left(r_{N}^{*}\right) & 0
\end{array}\right] .
$$


Since the collusion-maximization problem attains a maximum at $r^{*}$, the matrix above is negative semidefinite. Then, $f^{\prime \prime}\left(r_{C}^{*}\right)-e_{H}^{\prime \prime}\left(r_{C}^{*}\right)+\lambda^{*} e_{L}^{\prime \prime}\left(r_{C}^{*}\right) \leq 0$ and $-e_{H}^{\prime \prime}\left(r_{N}^{*}\right)+\lambda^{*} e_{L}^{\prime \prime}\left(r_{N}^{*}\right) \leq 0$. By $(7)$ and $\lambda^{*}=e_{H}^{\prime}\left(r_{N}^{*}\right) / e_{L}^{\prime}\left(r_{N}^{*}\right)$,

$$
e_{H}^{\prime \prime}\left(r_{N}^{*}\right)-\lambda^{*} e_{L}^{\prime \prime}\left(r_{N}^{*}\right)=e_{H}^{\prime \prime}\left(r_{N}^{*}\right)-\frac{e_{H}^{\prime}\left(r_{N}^{*}\right)}{e_{L}^{\prime}\left(r_{N}^{*}\right)} e_{L}^{\prime \prime}\left(r_{N}^{*}\right)=e_{H}^{\prime}\left(r_{N}^{*}\right)\left[\frac{e_{H}^{\prime \prime}\left(r_{N}^{*}\right)}{e_{H}^{\prime}\left(r_{N}^{*}\right)}-\frac{e_{L}^{\prime \prime}\left(r_{N}^{*}\right)}{e_{L}^{\prime}\left(r_{N}^{*}\right)}\right]>0 .
$$

Then,

$$
\operatorname{det} A_{L}=\left[e_{L}^{\prime}\left(r_{N}^{*}\right)\right]^{2}\left[-f^{\prime \prime}\left(r_{C}^{*}\right)+e_{H}^{\prime \prime}\left(r_{C}^{*}\right)-\lambda^{*} e_{L}^{\prime \prime}\left(r_{C}^{*}\right)\right]+\left[e_{L}^{\prime}\left(r_{C}^{*}\right)\right]^{2}\left[e_{H}^{\prime \prime}\left(r_{N}^{*}\right)-\lambda^{*} e_{L}^{\prime \prime}\left(r_{N}^{*}\right)\right]>0
$$

It follows from the Implicit Function Theorem that $r^{*}$ is a unique function of $w_{H}$ and differentiable. The Envelope Theorem entails that

$$
\frac{\partial V\left(w_{H}^{*}\right)}{\partial w_{H}}=-\lambda^{*}<0
$$

which in turn implies a corner solution at $w_{H}^{*}=\bar{w}_{L}$. However, if $w_{H}^{*}=\bar{w}_{L},\left(r_{C}^{*}, r_{N}^{*}\right)=$ $\left(r_{L}, r_{L}\right)$, and we have a contradiction with Proposition 2.

(i) Hence, both ICs in (19) must be binding. By adding two ICs,

$$
e_{L}\left(r_{C}^{*}\right)-e_{H}\left(r_{C}^{*}\right)-\left[e_{L}\left(r_{L}\right)-e_{H}\left(r_{L}\right)\right]+e_{L}\left(r_{N}^{*}\right)-e_{H}\left(r_{N}^{*}\right)-\left[e_{L}\left(r_{L}\right)-e_{H}\left(r_{L}\right)\right]=0 .
$$

Since $r_{N}^{*}>r_{L}$, SMP entails that $r_{C}^{*}<r_{L}$.

(ii) Since both ICs must be binding, from (18),

$$
\begin{aligned}
f^{\prime}\left(r_{C}^{*}\right)-e_{H}^{\prime}\left(r_{C}^{*}\right)-\mu^{*} e_{H}^{\prime}\left(r_{C}^{*}\right)+\lambda^{*} e_{L}^{\prime}\left(r_{C}^{*}\right) & =0, \\
-e_{H}^{\prime}\left(r_{N}^{*}\right)-\mu^{*} e_{H}^{\prime}\left(r_{N}^{*}\right)+\lambda^{*} e_{L}^{\prime}\left(r_{N}^{*}\right) & =0, \\
\delta w_{H}-\delta \bar{w}_{L}-\left[e_{H}\left(r_{C}^{*}\right)+e_{H}\left(r_{N}^{*}\right)\right]+\left[e_{H}\left(r_{L}\right)+e_{H}\left(r_{L}\right)\right] & =0, \\
\delta \bar{w}_{L}-\delta w_{H}+\left[e_{L}\left(r_{C}^{*}\right)+e_{L}\left(r_{N}^{*}\right)\right]-\left[e_{L}\left(r_{L}\right)+e_{L}\left(r_{L}\right)\right] & =0 .
\end{aligned}
$$

Denote

$$
\begin{aligned}
\alpha & :=f^{\prime \prime}\left(r_{C}^{*}\right)-e_{H}^{\prime \prime}\left(r_{C}^{*}\right)-\mu^{*} e_{H}^{\prime \prime}\left(r_{C}^{*}\right)+\lambda^{*} e_{L}^{\prime \prime}\left(r_{C}^{*}\right), \\
\beta & :=-e_{H}^{\prime \prime}\left(r_{N}^{*}\right)-\mu^{*} e_{H}^{\prime \prime}\left(r_{N}^{*}\right)+\lambda^{*} e_{L}^{\prime \prime}\left(r_{N}^{*}\right) .
\end{aligned}
$$

Define a matrix $\mathbf{A}$ as below:

$$
\mathbf{A}:=\left[\begin{array}{cccc}
\alpha & 0 & -e_{H}^{\prime}\left(r_{C}^{*}\right) & e_{L}^{\prime}\left(r_{C}^{*}\right) \\
0 & \beta & -e_{H}^{\prime}\left(r_{N}^{*}\right) & e_{L}^{\prime}\left(r_{N}^{*}\right) \\
-e_{H}^{\prime}\left(r_{C}^{*}\right) & -e_{H}^{\prime}\left(r_{N}^{*}\right) & 0 & 0 \\
e_{L}^{\prime}\left(r_{C}^{*}\right) & e_{L}^{\prime}\left(r_{N}^{*}\right) & 0 & 0
\end{array}\right]
$$


Then,

$\operatorname{det} \mathbf{A}=\left[e_{H}^{\prime}\left(r_{N}^{*}\right) e_{L}^{\prime}\left(r_{C}^{*}\right)-e_{H}^{\prime}\left(r_{C}^{*}\right) e_{L}^{\prime}\left(r_{N}^{*}\right)\right]^{2}=\left\{\left[e_{L}^{\prime}\left(r_{C}^{*}\right) e_{L}^{\prime}\left(r_{N}^{*}\right)\right]\left[\frac{e_{H}^{\prime}\left(r_{N}^{*}\right)}{e_{L}^{\prime}\left(r_{N}^{*}\right)}-\frac{e_{H}^{\prime}\left(r_{C}^{*}\right)}{e_{L}^{\prime}\left(r_{C}^{*}\right)}\right]\right\}^{2}$.

Moreover, since $r_{C}^{*}<r_{L}$ and $r_{N}^{*}>r_{L}$, SMP and the result in (i) above imply that $e_{L}^{\prime}\left(r_{C}^{*}\right) e_{L}^{\prime}\left(r_{N}^{*}\right)<0$, and

$$
\frac{e_{H}^{\prime}\left(r_{N}^{*}\right)}{e_{L}^{\prime}\left(r_{N}^{*}\right)}=\frac{p^{\prime}\left(r_{N}^{*}\right)+c_{H}^{\prime}\left(r_{N}^{*}\right)}{p^{\prime}\left(r_{N}^{*}\right)+c_{L}^{\prime}\left(r_{N}^{*}\right)}<1 \text { and } \frac{e_{H}^{\prime}\left(r_{C}^{*}\right)}{e_{L}^{\prime}\left(r_{C}^{*}\right)}=\frac{p^{\prime}\left(r_{C}^{*}\right)+c_{H}^{\prime}\left(r_{C}^{*}\right)}{p^{\prime}\left(r_{C}^{*}\right)+c_{L}^{\prime}\left(r_{C}^{*}\right)}>1,
$$

so we have

$$
e_{H}^{\prime}\left(r_{N}^{*}\right) e_{L}^{\prime}\left(r_{C}^{*}\right)-e_{H}^{\prime}\left(r_{C}^{*}\right) e_{L}^{\prime}\left(r_{N}^{*}\right)>0 .
$$

Hence, $\operatorname{det} \mathbf{A}>0$. It follows from the Implicit Function Theorem that $r^{*}$ is a unique function of $\left(w_{H}, \tau\right)$ and differentiable.

(iii) The Envelope Theorem entails that

$$
\frac{\partial V\left(w_{H}^{*}\right)}{\partial w_{H}}=\mu^{*}-\lambda^{*} .
$$

If $\mu^{*}-\lambda^{*} \neq 0$, a contradiction as above. Since the collusion-maximization problem attains a maximum at $r^{*}$, the matrix $D^{2} L$ from (17) is negative semidefinite. Then, $\alpha \leq 0$ and $\beta \leq 0$. Write a matrix:

$$
\mathbf{A}\left[\begin{array}{c}
\frac{\partial r_{C}^{*}}{\partial w_{H}} \\
\frac{\partial r_{N}^{*}}{\partial w_{H}} \\
\frac{\partial \mu^{*}}{\partial w_{H}} \\
\frac{\partial \lambda^{*}}{\partial w_{H}}
\end{array}\right]=\left[\begin{array}{c}
0 \\
0 \\
-\delta \\
\delta
\end{array}\right]
$$

The Cramer's rule entails

$$
\frac{\partial \mu^{*}\left(w_{H}^{*}(s), s\right)}{\partial w_{H}}-\frac{\partial \lambda^{*}\left(w_{H}^{*}(s), s\right)}{\partial w_{H}}=\frac{\delta\left\{\alpha\left[e_{L}^{\prime}\left(r_{N}^{*}\right)-e_{H}^{\prime}\left(r_{N}^{*}\right)\right]^{2}+\beta\left[e_{L}^{\prime}\left(r_{C}^{*}\right)-e_{H}^{\prime}\left(r_{C}^{*}\right)\right]^{2}\right\}}{\operatorname{det} \mathbf{A}} .
$$

It follows from (7) that $\beta<0$. Suppose $\beta=0$, by (26),

$$
\mu^{*}=\lambda^{*}=\frac{e_{H}^{\prime \prime}\left(r_{N}^{*}\right)}{e_{L}^{\prime \prime}\left(r_{N}^{*}\right)-e_{H}^{\prime \prime}\left(r_{N}^{*}\right)} .
$$

On the other hand, by the first order conditions,

$$
\mu^{*}=\lambda^{*}=\frac{e_{H}^{\prime}\left(r_{N}^{*}\right)}{e_{L}^{\prime}\left(r_{N}^{*}\right)-e_{H}^{\prime}\left(r_{N}^{*}\right)},
$$

which implies that

$$
\frac{e_{H}^{\prime \prime}\left(r_{N}^{*}\right)}{e_{H}^{\prime}\left(r_{N}^{*}\right)}=\frac{e_{L}^{\prime \prime}\left(r_{N}^{*}\right)}{e_{L}^{\prime}\left(r_{N}^{*}\right)}
$$


This violates the assumption (7). Hence,

$$
\frac{\partial \mu^{*}\left(w_{H}^{*}(s), s\right)}{\partial w_{H}}-\frac{\partial \lambda^{*}\left(w_{H}^{*}(s), s\right)}{\partial w_{H}}<0
$$

The result follows from the Implicit Function Theorem.

Proof of Proposition 5. First, we can derive the following condition between $w_{H}^{*}$ and a parameter $\tau$.

$$
\begin{aligned}
0 & =\frac{\partial \mu^{*}\left(w_{H}^{*}(\tau), \tau\right)}{\partial w_{H}} \frac{\partial w_{H}^{*}}{\partial \tau}+\frac{\partial \mu^{*}\left(w_{H}^{*}(\tau), \tau\right)}{\partial \tau}-\left[\frac{\partial \lambda^{*}\left(w_{H}^{*}(\tau), \tau\right)}{\partial w_{H}} \frac{\partial w_{H}^{*}}{\partial \tau}+\frac{\partial \lambda^{*}\left(w_{H}^{*}(\tau), \tau\right)}{\partial \tau}(3)\right. \\
& =\left[\frac{\partial \mu^{*}\left(w_{H}^{*}(\tau), \tau\right)}{\partial w_{H}}-\frac{\partial \lambda^{*}\left(w_{H}^{*}(\tau), \tau\right)}{\partial w_{H}}\right] \frac{\partial w_{H}^{*}}{\partial \tau}+\left[\frac{\partial \mu^{*}\left(w_{H}^{*}(\tau), \tau\right)}{\partial \tau}-\frac{\partial \lambda^{*}\left(w_{H}^{*}(\tau), \tau\right)}{\partial \tau}\right]
\end{aligned}
$$

We divide the proof into three steps.

Step 1. $\frac{\partial r_{C}^{*}}{\partial w_{H}}<0, \frac{\partial r_{N}^{*}}{\partial w_{H}}>0$. Write a matrix in (28). Note that by SMP and (27), $\operatorname{det}\left[\begin{array}{cccc}0 & 0 & -e_{H}^{\prime}\left(r_{C}^{*}\right) & e_{L}^{\prime}\left(r_{C}^{*}\right) \\ 0 & \beta & -e_{H}^{\prime}\left(r_{N}^{*}\right) & e_{L}^{\prime}\left(r_{N}^{*}\right) \\ -\delta & -e_{H}^{\prime}\left(r_{N}^{*}\right) & 0 & 0 \\ \delta & e_{L}^{\prime}\left(r_{N}^{*}\right) & 0 & 0\end{array}\right]=\delta\left[e_{H}^{\prime}\left(r_{N}^{*}\right)-e_{L}^{\prime}\left(r_{N}^{*}\right)\right]\left[e_{H}^{\prime}\left(r_{N}^{*}\right) e_{L}^{\prime}\left(r_{C}^{*}\right)-e_{H}^{\prime}\left(r_{C}^{*}\right) e_{L}^{\prime}\left(r_{N}^{*}\right)\right]<0$

The Cramer's rule entails

$$
\frac{\partial r_{C}^{*}}{\partial w_{H}}=\frac{\delta\left[e_{H}^{\prime}\left(r_{N}^{*}\right)-e_{L}^{\prime}\left(r_{N}^{*}\right)\right]\left[e_{H}^{\prime}\left(r_{N}^{*}\right) e_{L}^{\prime}\left(r_{C}^{*}\right)-e_{H}^{\prime}\left(r_{C}^{*}\right) e_{L}^{\prime}\left(r_{N}^{*}\right)\right]}{\operatorname{det} \mathbf{A}}<0 .
$$

Similarly,

$$
\frac{\partial r_{N}^{*}}{\partial w_{H}}=\frac{\delta\left[e_{L}^{\prime}\left(r_{C}^{*}\right)-e_{H}^{\prime}\left(r_{C}^{*}\right)\right]\left[e_{H}^{\prime}\left(r_{N}^{*}\right) e_{L}^{\prime}\left(r_{C}^{*}\right)-e_{H}^{\prime}\left(r_{C}^{*}\right) e_{L}^{\prime}\left(r_{N}^{*}\right)\right]}{\operatorname{det} \mathbf{A}}>0
$$

Step 2. $\frac{\partial w_{H}^{*}}{\partial s}>0$. Write a matrix:

$$
\mathbf{A}\left[\begin{array}{c}
\frac{\partial r_{C}^{*}}{\partial s} \\
\frac{\partial r_{N}^{*}}{\partial s} \\
\frac{\partial \mu^{*}}{\partial s} \\
\frac{\partial \lambda^{*}}{\partial s}
\end{array}\right]=\left[\begin{array}{c}
-\frac{\partial^{2} f\left(r_{C}^{*}, s\right)}{\partial r_{C} \partial s} \\
0 \\
0 \\
0
\end{array}\right]
$$

The Cramer's rule entails

$$
\frac{\partial \mu^{*}\left(w_{H}^{*}(s), s\right)}{\partial s}-\frac{\partial \lambda^{*}\left(w_{H}^{*}(s), s\right)}{\partial s}=\frac{-\frac{\partial^{2} f\left(r_{C}^{*}, s\right)}{\partial r_{C} \partial s}\left[e_{L}^{\prime}\left(r_{N}^{*}\right)-e_{H}^{\prime}\left(r_{N}^{*}\right)\right]\left[e_{H}^{\prime}\left(r_{N}^{*}\right) e_{L}^{\prime}\left(r_{C}^{*}\right)-e_{H}^{\prime}\left(r_{C}^{*}\right) e_{L}^{\prime}\left(r_{N}^{*}\right)\right]}{\operatorname{det} \mathbf{A}}>0
$$


The last inequality follows from (27) and SMP. (30) and (29) imply the result.

Step 3. $\frac{\partial r_{C}^{*}}{\partial s}=\frac{\partial r_{N}^{*}}{\partial s}=0$. Using the matrix in Step 2, it can be easily shown.

Therefore,

$$
\begin{aligned}
\frac{d r_{C}^{*}\left(w_{H}^{*}(s), s\right)}{d s} & =\frac{\partial r_{C}^{*}\left(w_{H}^{*}(s), s\right)}{\partial w_{H}} \frac{\partial w_{H}^{*}}{\partial s}+\frac{\partial r_{C}^{*}\left(w_{H}^{*}(s), s\right)}{\partial s}<0, \\
\frac{d r_{N}^{*}\left(w_{H}^{*}(s), s\right)}{d s} & =\frac{\partial r_{N}^{*}\left(w_{H}^{*}(s), s\right)}{\partial w_{H}} \frac{\partial w_{H}^{*}}{\partial s}+\frac{\partial r_{N}^{*}\left(w_{H}^{*}(s), s\right)}{\partial s}>0 .
\end{aligned}
$$

Proof of Proposition 6. Post-government-employment restrictions make each regulator attain a lower discounted present-value of a future wage. (25) can be rewritten as

$$
\begin{aligned}
f^{\prime}\left(r_{C}^{*}\right)-e_{H}^{\prime}\left(r_{C}^{*}\right)-\mu^{*} e_{H}^{\prime}\left(r_{C}^{*}\right)+\lambda^{*} e_{L}^{\prime}\left(r_{C}^{*}\right) & =0, \\
-e_{H}^{\prime}\left(r_{N}^{*}\right)-\mu^{*} e_{H}^{\prime}\left(r_{N}^{*}\right)+\lambda^{*} e_{L}^{\prime}\left(r_{N}^{*}\right) & =0, \\
\delta\left(w_{H}-\bar{w}_{L}\right)-\left[e_{H}\left(r_{C}^{*}\right)+e_{H}\left(r_{N}^{*}\right)\right]+\left[e_{H}\left(r_{L}\right)+e_{H}\left(r_{L}\right)\right] & =0, \\
\delta\left(\bar{w}_{L}-w_{H}\right)+\left[e_{L}\left(r_{C}^{*}\right)+e_{L}\left(r_{N}^{*}\right)\right]-\left[e_{L}\left(r_{L}\right)+e_{L}\left(r_{L}\right)\right] & =0 .
\end{aligned}
$$

Write a matrix:

$$
\mathbf{A}\left[\begin{array}{c}
\frac{\partial r_{C}^{*}}{\partial \delta} \\
\frac{\partial r_{N}^{*}}{\partial \delta} \\
\frac{\partial \mu^{*}}{\partial \delta} \\
\frac{\partial \lambda^{*}}{\partial \delta}
\end{array}\right]=\left[\begin{array}{c}
0 \\
0 \\
-\left(w_{H}-\bar{w}_{L}\right) \\
w_{H}-\bar{w}_{L}
\end{array}\right]
$$

The Cramer's rule entails

$\frac{\partial \mu^{*}\left(w_{H}^{*}(\delta), \delta\right)}{\partial \delta}-\frac{\partial \lambda^{*}\left(w_{H}^{*}(\delta), \delta\right)}{\partial \delta}=\frac{\left(w_{H}-\bar{w}_{L}\right)\left\{\alpha\left[e_{L}^{\prime}\left(r_{N}^{*}\right)-e_{H}^{\prime}\left(r_{N}^{*}\right)\right]^{2}+\beta\left[e_{L}^{\prime}\left(r_{C}^{*}\right)-e_{H}^{\prime}\left(r_{C}^{*}\right)\right]^{2}\right\}}{\operatorname{det} \mathbf{A}}$

It follows from (30) and (29) that

$$
\frac{\partial w_{H}^{*}}{\partial \delta}=-\left(w_{H}-\bar{w}_{L}\right)
$$

In addition,

$$
\begin{aligned}
\frac{\partial r_{C}^{*}\left(w_{H}^{*}(\delta), \delta\right)}{\partial \delta} & =\frac{\left(w_{H}-\bar{w}_{L}\right)\left[e_{H}^{\prime}\left(r_{N}^{*}\right)-e_{L}^{\prime}\left(r_{N}^{*}\right)\right]\left[e_{H}^{\prime}\left(r_{N}^{*}\right) e_{L}^{\prime}\left(r_{C}^{*}\right)-e_{H}^{\prime}\left(r_{C}^{*}\right) e_{L}^{\prime}\left(r_{N}^{*}\right)\right]}{\operatorname{det} \mathbf{A}}<0 \\
\frac{\partial r_{N}^{*}\left(w_{H}^{*}(\delta), \delta\right)}{\partial \delta} & =\frac{\left(w_{H}-\bar{w}_{L}\right)\left[e_{L}^{\prime}\left(r_{C}^{*}\right)-e_{H}^{\prime}\left(r_{C}^{*}\right)\right]\left[e_{H}^{\prime}\left(r_{N}^{*}\right) e_{L}^{\prime}\left(r_{C}^{*}\right)-e_{H}^{\prime}\left(r_{C}^{*}\right) e_{L}^{\prime}\left(r_{N}^{*}\right)\right]}{\operatorname{det} \mathbf{A}}>0 .
\end{aligned}
$$


(31) and (32) with the results above imply

$$
\begin{aligned}
\frac{d r_{C}^{*}\left(w_{H}^{*}(\delta), \delta\right)}{d \delta} & =\frac{\partial r_{C}^{*}\left(w_{H}^{*}(\delta), \delta\right)}{\partial w_{H}} \frac{\partial w_{H}^{*}}{\partial \delta}+\frac{\partial r_{C}^{*}\left(w_{H}^{*}(\delta), \delta\right)}{\partial \delta}=0, \\
\frac{d r_{N}^{*}\left(w_{H}^{*}(\delta), \delta\right)}{d \delta} & =\frac{\partial r_{N}^{*}\left(w_{H}^{*}(\delta), \delta\right)}{\partial w_{H}} \frac{\partial w_{H}^{*}}{\partial \delta}+\frac{\partial r_{N}^{*}\left(w_{H}^{*}(s), \delta\right)}{\partial \delta}=0 .
\end{aligned}
$$

Proof of Proposition 7. Denote $\gamma:=\left[\frac{\partial p\left(r_{L}, t\right)}{\partial t}-\frac{\partial p\left(r_{C}^{*}, t\right)}{\partial t}\right]+\left[\frac{\partial p\left(r_{L}, t\right)}{\partial t}-\frac{\partial p\left(r_{N}^{*}, t\right)}{\partial t}\right]$.

Write a matrix:

$$
\mathbf{A}\left[\begin{array}{c}
\frac{\partial r_{C}^{*}}{\partial t} \\
\frac{\partial r_{N}^{*}}{\partial t} \\
\frac{\partial \mu^{*}}{\partial t} \\
\frac{\partial \lambda^{*}}{\partial t}
\end{array}\right]=\left[\begin{array}{c}
\left(1+\mu^{*}-\lambda^{*}\right) d \\
\left(1+\mu^{*}-\lambda^{*}\right) d \\
-\gamma \\
\gamma
\end{array}\right]
$$

From Proposition $4, \mu^{*}-\lambda^{*}=0$. Then,

$$
\mathbf{A}\left[\begin{array}{c}
\frac{\partial r_{C}^{*}}{\partial t} \\
\frac{\partial r_{N}^{*}}{\partial t} \\
\frac{\partial \mu^{*}}{\partial t} \\
\frac{\partial \lambda^{*}}{\partial t}
\end{array}\right]=\left[\begin{array}{c}
d \\
d \\
-\gamma \\
\gamma
\end{array}\right]
$$

The Cramer's rule entails

$$
\begin{aligned}
& \frac{\partial \mu^{*}\left(w_{H}^{*}(t), t\right)}{\partial t}-\frac{\partial \lambda^{*}\left(w_{H}^{*}(t), t\right)}{\partial t} \\
= & \frac{\gamma\left\{\alpha\left[e_{L}^{\prime}\left(r_{N}^{*}\right)-e_{H}^{\prime}\left(r_{N}^{*}\right)\right]^{2}+\beta\left[e_{L}^{\prime}\left(r_{C}^{*}\right)-e_{H}^{\prime}\left(r_{C}^{*}\right)\right]^{2}\right\}}{\operatorname{det} \mathbf{A}} \\
& +\frac{d\left\{e_{L}^{\prime}\left(r_{N}^{*}\right)-e_{H}^{\prime}\left(r_{N}^{*}\right)-\left[e_{L}^{\prime}\left(r_{C}^{*}\right)-e_{H}^{\prime}\left(r_{C}^{*}\right)\right]\right\}\left[e_{H}^{\prime}\left(r_{N}^{*}\right) e_{L}^{\prime}\left(r_{C}^{*}\right)-e_{H}^{\prime}\left(r_{C}^{*}\right) e_{L}^{\prime}\left(r_{N}^{*}\right)\right]}{\operatorname{det} \mathbf{A}}
\end{aligned}
$$

It follows from (30) and (29) that

$$
\frac{\partial w_{H}^{*}}{\partial t}=-\gamma-\frac{d\left\{e_{L}^{\prime}\left(r_{N}^{*}\right)-e_{H}^{\prime}\left(r_{N}^{*}\right)-\left[e_{L}^{\prime}\left(r_{C}^{*}\right)-e_{H}^{\prime}\left(r_{C}^{*}\right)\right]\right\}\left[e_{H}^{\prime}\left(r_{N}^{*}\right) e_{L}^{\prime}\left(r_{C}^{*}\right)-e_{H}^{\prime}\left(r_{C}^{*}\right) e_{L}^{\prime}\left(r_{N}^{*}\right)\right]}{\left\{\alpha\left[e_{L}^{\prime}\left(r_{N}^{*}\right)-e_{H}^{\prime}\left(r_{N}^{*}\right)\right]^{2}+\beta\left[e_{L}^{\prime}\left(r_{C}^{*}\right)-e_{H}^{\prime}\left(r_{C}^{*}\right)\right]^{2}\right\}} .
$$

Denote

$$
\Gamma:=\frac{d\left\{e_{L}^{\prime}\left(r_{N}^{*}\right)-e_{H}^{\prime}\left(r_{N}^{*}\right)-\left[e_{L}^{\prime}\left(r_{C}^{*}\right)-e_{H}^{\prime}\left(r_{C}^{*}\right)\right]\right\}\left[e_{H}^{\prime}\left(r_{N}^{*}\right) e_{L}^{\prime}\left(r_{C}^{*}\right)-e_{H}^{\prime}\left(r_{C}^{*}\right) e_{L}^{\prime}\left(r_{N}^{*}\right)\right]}{\left\{\alpha\left[e_{L}^{\prime}\left(r_{N}^{*}\right)-e_{H}^{\prime}\left(r_{N}^{*}\right)\right]^{2}+\beta\left[e_{L}^{\prime}\left(r_{C}^{*}\right)-e_{H}^{\prime}\left(r_{C}^{*}\right)\right]^{2}\right\}} .
$$


Then, SMP, (27) and (8) entail $\Gamma>0$. In addition,

$$
\begin{aligned}
\frac{\partial r_{C}^{*}\left(w_{H}^{*}(t), t\right)}{\partial t} & =\frac{\gamma\left[e_{H}^{\prime}\left(r_{N}^{*}\right)-e_{L}^{\prime}\left(r_{N}^{*}\right)\right]\left[e_{H}^{\prime}\left(r_{N}^{*}\right) e_{L}^{\prime}\left(r_{C}^{*}\right)-e_{H}^{\prime}\left(r_{C}^{*}\right) e_{L}^{\prime}\left(r_{N}^{*}\right)\right]}{\operatorname{det} \mathbf{A}} \\
\frac{\partial r_{N}^{*}\left(w_{H}^{*}(t), t\right)}{\partial t} & =\frac{\gamma\left[e_{L}^{\prime}\left(r_{C}^{*}\right)-e_{H}^{\prime}\left(r_{C}^{*}\right)\right]\left[e_{H}^{\prime}\left(r_{N}^{*}\right) e_{L}^{\prime}\left(r_{C}^{*}\right)-e_{H}^{\prime}\left(r_{C}^{*}\right) e_{L}^{\prime}\left(r_{N}^{*}\right)\right]}{\operatorname{det} \mathbf{A}}
\end{aligned}
$$

(31) and (32) with the results above imply

$$
\begin{aligned}
\frac{d r_{C}^{*}\left(w_{H}^{*}(t), t\right)}{d t} & =\frac{\partial r_{C}^{*}\left(w_{H}^{*}(t), t\right)}{\partial w_{H}} \frac{\partial w_{H}^{*}}{\partial t}+\frac{\partial r_{C}^{*}\left(w_{H}^{*}(t), t\right)}{\partial t}=\frac{\partial r_{C}^{*}\left(w_{H}^{*}(t), t\right)}{\partial w_{H}}(-\Gamma)>0, \\
\frac{d r_{N}^{*}\left(w_{H}^{*}(t), t\right)}{d t} & =\frac{\partial r_{N}^{*}\left(w_{H}^{*}(t), t\right)}{\partial w_{H}} \frac{\partial w_{H}^{*}}{\partial t}+\frac{\partial r_{N}^{*}\left(w_{H}^{*}(s), t\right)}{\partial t}=\frac{\partial r_{N}^{*}\left(w_{H}^{*}(t), t\right)}{\partial w_{H}}(-\Gamma)<0 .
\end{aligned}
$$

\section{References}

Adams, G. (1982), Politics of Defense Contacting. New Brunswick, N.J., Transactions Publishers.

Armstrong, M. and Sappington, D.E.M. (2007), Recent Developments in the Theory of Regulation, Handbook of Industrial Organization, vol. 3 ed. by Armstrong, M. and Porter, R.H. North Holland, 1557-1700

Brezis, E. and Weiss, A. (1997), Conscientious regulation and post-regulatory employment restrictions, European Journal of Political Economy 13, 517-536.

Che, Y.-K. (1995), Revolving door and the optimal tolerance for agency collusion, Rand Journal of Economics 26, 378-397.

Cho, I.-K. and Kreps, D.M. (1987), Signaling games and stable equilibria, Quarterly Journal of Economics 102, 179-222.

Dal Bo, E. (2006), Regulatory capture: a review, Oxford Review of Economic Policy 22, 203-225.

Eckert, R.D. (1981), The life cycle of regulatory commissioners, Journal of Law and Economics 24, 113-120. 
Elliott, K.A. (1997), Corruption and The Global Economy. Washington, D.C., Institute for International Economics.

Gely, R. and Zardkoohi, A. (2001), Measuring the effects of post-government-employment restrictions, American Law and Economics Review 3, 288-301.

Fudenberg, D., Kreps, D.M. and Maskin, E.S. (1990), Repeated games with long-run and short-run players, Review of Economic Studies 57, 555-573.

Fudenberg, D. and Tirole, J. (1991), Perfect Bayesian equilibrium and sequential equilibrium, Journal of Economic Theory 53, 236-260.

Klitgaard, R. (1988) Controlling Corruption. University of California Press, Berkeley.

Kreps, D. (1990), Corporate culture and economic theory. In: J. Alt and K. Shepsle (eds.): Perspectives on Positive Political Economy, Cambridge, U.K., Cambridge University Press

Laffont, J.J. and Tirole, J. (1996), A Theory of Incentives in Procurement and Regulation, The MIT Press, Cambridge, MA

Lambert-Mogiliansky, A., Majumdar, M. and Radner, R. (2007), Strategic analysis of petty corruption: entrepreneurs and bureaucrats, Journal of Development Economics 83, 351367.

Martimot, D. (1999), The life cycle of regulatory agencies: dynamic capture and transaction costs, Review of Economic Studies 66, 929-947.

Milgrom, P. and Segal, I. (2002), Envelope theorems for arbitrary choice sets, Econometrica 70, 583-601.

Milgrom, P. and Shannon, C. (1994), Monotone Comparative Statics, Econometrica 62, 157-180.

Quah, J.K.-H. (2007), The comparative statics of constrained optimization problems, Econometrica 75, 401-431. 
Rose-Ackerman, S.: Corruption and Government. Cambridge, U.K.: Cambridge University Press (1999)

Salant, D.J. (1995), Behind the revolving door: a new view of public utility regulation, Rand Journal of Economics 26, 362-377.

Spence, M. (1973), Job market signaling, Quarterly Journal of Economics 87, 355-374. 